\title{
True-Amplitude Processing Techniques for Marine, Crustal-Reflection Seismic Data
}

\section{U.S. GEOLOGICAL SURVEY BULLETIN 1897}


Instructions on ordering publications of the U.S. Geological Survey, along with prices of the last offerings, are given in the current-year issues of the monthly catalog "New Publications of the U.S. Geological Survey." Prices of available U.S. Geological Survey publications released prior to the current year are listed in the most recent annual "Price and Availability List." Publications that are listed in various U.S. Geological Survey catalogs (see back inside cover) but not listed in the most recent annual "Price and Availability List" are no longer available.

Prices of reports released to the open files are given in the listing "U.S. Geological Survey Open-File Reports," updated monthly, which is for sale in microfiche from the U.S. Geological Survey, Books and Open-File Reports Section, Federal Center, Box 25425, Denver, CO 80225. Reports released through the NTIS may be obtained by writing to the National Technical Information Service, U.S. Department of Commerce, Springfield, VA 22161; please include NTIS report number with inquiry.

Order U.S. Geologizal Survey publications by mail or over the counter from the offices given below.

\section{BY MAIL}

\section{Books}

Professional Papers, Bulletins, Water-Supply Papers, Techniques of Water-Resources Investigations, Circulars, publications of general interest (such as leaflets, pamphlets, booklets), single copies of Earthquakes \& Volcanoes, Preliminary Determination of Epicenters, and some miscellaneous reports, including some of the foregoing series that have gone out of print at the Superintendent of Documents, are obtainable by mail from

\section{U.S. Geological Survey, Books and Open-File Reports Federal Center, Box 25425 Denver, CO 80225}

Subscriptions to periodicals (Earthquakes \& Volcanoes and Preliminary Determination of Epicenters) can be obtained ONLY from the

\section{Superintendent of Documents \\ Government Printing Office \\ Washington, D.C. 20402}

(Check or money order must be payable to Superintendent of Documents.)

\section{Maps}

For maps, address mail orders to

$$
\begin{gathered}
\text { U.S. Geological Survey, Map Distribution } \\
\text { Federal Center, Box } 25286 \\
\text { Denver, CO } 80225
\end{gathered}
$$

Residents of Alaska may order maps from

$$
\begin{gathered}
\text { Alaska Distribution Section, U.S. Geological Survey, } \\
\text { New Federal Building - Box } 12 \\
101 \text { Twelfth Ave., Fairbanks, AK } 99701
\end{gathered}
$$

\section{OVER THE COUNTER}

\section{Books}

Books of the U.S. Geological Survey are available over the counter at the following Geological Survey Public Inquiries Offices, all of which are authorized agents of the Superintendent of Documents:

- WASHINGTON, D.C.--Main Interior Bldg., 2600 corridor, 18 th and C Sts., NW.

- DENVER, Colorado--Federal Bldg., Rm. 169, 1961 Stout St.

- LOS ANGELES, California--Federal Bldg., Rm. 7638, 300 N. Los Angeles St.

- MENLO PARK, California--Bldg. 3 (Stop 533), Rm. 3128, 345 Middlefield Rd.

- RESTON, Virginia--503 National Center, Rm. 1C402, 12201 Sunrise Valley Dr.

- SALT LAKE CITY, Utah--Federal Bldg., Rm. 8105, 125 South State St.

- SAN FRANCISCO, California--Customhouse, Rm. 504, 555 Battery St.

- SPOKANE, Washington--U.S. Courthouse, Rm. 678, West 920 Riverside Ave..

- ANCHORAGE, Alaska--Rm. 101, 4230 University Dr.

- ANCHORAGE, Alaska--Federal Bldg, Rm. E-146, 701 C St.

\section{Maps}

Maps may be purchased over the counter at the U.S. Geological Survey offices where books are sold (all addresses in above list) and at the following Geological Survey offices:

- ROLLA, Missouri--1400 Independence Rd.

- DENVER, Colorado--Map Distribution, Bldg. 810, Federal Center

- FAIRBANKS, Alaska--New Federal Bldg., 101 Twelfth Ave. 
True-Amplitude Processing Techniques for Marine, Crustal-Reflection Seismic Data

By MYUNG W. LEE and DEBORAH R. HUTCHINSON

U.S. GEOLOGICAL SURVEY BULLETIN 1897 


\section{DEPARTMENT OF THE INTERIOR MANUEL LUJAN, JR., Secretary \\ U.S. GEOLOGICAL SURVEY \\ Dallas L. Peck, Director}

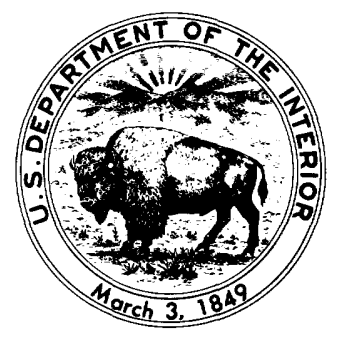

Any use of trade, product, or firm names in this publication is for descriptive purposes only and does not imply endorsement by the U.S. Government.

For sale by the

Books and Open-File Reports Section

U.S. Geological Survey

Federal Center

Box 25425

Denver, CO 80225

\section{Library of Congress Cataloging-in-Publication Data}

True-amplitude processing techniques for marine, crustal-reflection seismic data, by Myung W. Lee and Deborah R. Hutchinson.

p. cm.-(U.S. Geological Survey bulletin ; 1897)

Includes bibliographical references.

Supt. of Docs. no.: I 19.3:1897

1. Seismic reflection method-Data processing. 2. Earth-Crust. 3. Submarine geology-Superior, Lake. 4. Signal processing. I. Hutchinson, Deborah R. II. Title. III. Series.

QE75.B9

[QE33]

$557.3 \mathrm{~s}-\mathrm{dc} 20$

[551.1'3]

no. 1897 


\title{
CONTENTS
}

\author{
Abstract 1 \\ Introduction $\mathbf{1}$ \\ Acknowledgments $\mathbf{2}$ \\ Signal-to-noise ratio consideration $\mathbf{2}$ \\ Automatic trace editing $\mathbf{2}$ \\ Weighted stack $\mathbf{3}$ \\ Seismic data 4 \\ True-amplitude processing $\mathbf{5}$ \\ Comparison of the methods 10 \\ Post-stack adjustment 14 \\ Discussion 15 \\ Conclusions 20 \\ References cited 21 \\ Appendix $1 \quad 22$
}

\section{FIGURES}

1. Graph showing signal-to-noise ratio improvement by an edited and weighted stacking for two-channel noise model $\mathbf{5}$

2. Map of the Great Lakes area showing location of GLIMPCE seismic reflection lines and simplified geology 6

3. Stacked profiles with and without true-amplitude processing $\mathbf{8}$

4-8. Traces showing:

4. Comparison of vertical amplitude variation with and without trueamplitude processing $\mathbf{9}$

5. Examples of true-amplitude processing for part of line $\mathbf{A}$ on figure 2 with and without post-stack amplitude adjustment $\mathbf{1 1}$

6. Example of true-amplitude processing for part of line $\mathbf{A}$ on figure 2 by single-trace, root-mean-square equalization with and without post-stack amplitude adjustment 12

7. Example of true-amplitude processing for part of line A on figure 2 by a common-depth-point gather, root-mean-square equalization with and without post-stack amplitude adjustment 13

8. Comparison of vertical amplitude variation for true-amplitude-processed traces 14

9. True-amplitude-processed stacked section of line $\mathrm{C}$ on figure 2 without post-stack amplitude adjustment 16

10. Traces showing comparison of migration result for true-amplitude-processed section for line A on figure $2 \quad \mathbf{1 7}$

11. True-amplitude-processed section with post-stack amplitude adjustment for line $\mathrm{C}$ on figure $2 \quad \mathbf{1 8}$

12. True-amplitude-processed section with post-stack amplitude adjustment for line A on figure $2 \quad 19$ 



\title{
True-Amplitude Processing Techniques for Marine, Crustal-Reflection Seismic Data
}

\author{
By Myung W. Lee and Deborah R. Hutchinson
}

\begin{abstract}
Preserving the relative true-amplitude of seismic traces provides significant advantages for deep crustal investigations, particularly for the identification and analysis of deep reflections originating near the crust-mantle boundary. Preserving lateral variations along deep reflections is also important for resolving amplitude changes due to geologic causes rather than to artifacts from recording or source conditions.

Three relative true-amplitude processing methods (automatic edit, single-trace equalization, and a common-depthpoint gather equalization) were applied to the 20 -second seismic data of the Great Lakes Multidisciplinary Program on Crustal Evolution in order to evaluate the performance of the different techniques. Particular attention was paid to the improvement of signal-to-noise ratio and to the preservation of lateral continuity of the deep reflections.

This study indicates that the automatic editing procedure based on the median amplitude of a common-depth-point gather provided substantial signal-to-noise ratio improvement of the seismic profiles. Post-stack amplitude balancing was commonly necessary to maintain the lateral continuity of the deep reflections and to reduce migration noise. The results from these processing strategies confirm the existence of large differences in crustal reflectivities and in the shape and geometry of crust-mantle transition beneath central and western Lake Superior.
\end{abstract}

\section{INTRODUCTION}

Conventional seismic data processing techniques using automatic gain control (AGC) work well for imaging the gross structural component of upper to middle crustal regions from deep crustal seismic data. However, it is sometimes difficult to make visual interpretations of deeper reflections; that is, reflections from the lower crust and upper mantle, owing to the lack of amplitude contrast between signal and back-scattering noise. In order to differentiate signal from noise for deep reflections, it is advantageous to have information about both the relative true amplitude and lateral coherency of primary reflections. In contrast to AGC processing, relative true-amplitude (RTA) processing (sometimes referred to as true-amplitude (TA) processing) yields much more information about the relative strength of the reflections, thereby providing pertinent information about acoustic impedance and, potentially, about lithologic properties causing deep reflections.

Manuscript approved for publication, June 7, 1989.
The RTA processing technique has been used for direct hydrocarbon detection from the early 1970's, and Anstey (1977) provided many examples of trueamplitude sections. Recently, amplitude variation with offset distance has been used to characterize hydrocarbons, stratigraphic trap exploration, and reservoir analysis (Backus, 1987). Yu (1985) provided a detailed analysis of amplitude variation with offset to evaluate reservoir quality.

Because of additional processing efforts (and therefore additional cost), TA processing has not been routinely applied to deep reflection data, although its use is becoming more common. Grow (1980) used TA processing to interpret two sets of anomalously high amplitude events between 6 and $7.5 \mathrm{~s}$ (seconds) as continental basement and possible synrift volcanic units associated with the East Coast Magnetic Anomaly. Highamplitude events on the COCORP (Consortium for Continental Reflection Profiling) Death Valley profile were interpreted as evidence of a mid-crust magma chamber (de Voogd and others, 1986). RTA processing has been used to estimate reflection coefficients and to interpret strong reflections within the upper mantle (Warner and McGeary, 1987). Recently, Mayrand and Milkereit (1988) analyzed the Vancouver Island deep crustal profiles and concluded that the amplitude anomaly near the top of the subducting Juan de Fuca plate cannot be explained by changing recording conditions alone, implying some significant geological cause. These examples emphasize the significance of true-amplitude processing both for exploration and deep crustal study.

In order to preserve relative true amplitude, we must consider two amplitude correction procedures for TA processing. The first is to eliminate the propagation effect on the vertical amplitude variation, such as spherical divergence, transmission, and attenuation. The second is to minimize the lateral amplitude variation due to the source strength changes, receiver coupling variation, or near-surface inhomogeneities. In the present paper, we focus on preserving, rather than correcting, vertical and lateral amplitude variations. Two of the major problems in true-amplitude processing are as follows: (1) degradation of signal-to-noise ratio (SNR) due to anomalously high noise bursts, and (2) abrupt lateral amplitude changes due to the nearsurface effects. Therefore, we placed particular empha- 
sis on pre-stack processing to increase SNR for stacking and on post-stack amplitude adjustment to suppress the near-surface effects.

Three different techniques-automatic editing, single-trace equalization, and a common-depth-point (CDP) gather equalization-are discussed and applied to the GLIMPCE (Great Lakes Multidisciplinary Program on Crustal Evolution) seismic data. Trueamplitude processing using an automatic editing procedure was discussed by Mayrand and Milkereit (1988); our approach is similar to theirs. Yu (1985) discussed different equalization methods for true-amplitude processing; the single-trace equalization method is similar to the windowed-trace equalization method discussed by Yu. A CDP gather equalization method is also investigated here in an attempt to improve lateral continuity of the deep reflections.

All three methods preserve the vertical amplitude variation quite satisfactorily, but lateral amplitude preservation is difficult to obtain. Post-stack amplitude adjustment is generally required in order to avoid abrupt lateral amplitude variation.

In this paper, we initially take a theoretical approach and develop a trace model that can be used to evaluate SNR improvement by either an edited or weighted stack. A hypothetical two-trace stack of varying SNR provides a simple case to illustrate the range of possible SNR improvement. We then describe the GLIMPCE seismic data and the three TA processing techniques. Finally, we compare the results and discuss post-stack amplitude adjustment.

\section{Acknowledgments}

The data described in this paper were collected by Geophysical Services, Inc., and the GLIMPCE project was funded jointly by the Geological Survey of Canada and the U.S. Geological Survey. Our sincere appreciation is extended to all the GLIMPCE members, and, in particular, to William Cannon, John Behrendt, and Alan Green. We thank Jill McCarthy and John Miller for reviewing the manuscript. All data were processed on a VAX 11/780 computer using CogniSeis' DISCO software with additional programs developed by U.S. Geological Survey personnel.

\section{SIGNAL-TO-NOISE RATIO CONSIDERATION}

Improvement of SNR is always desirable for seismic data processing, and it is particularly important for deep crustal studies where signal strength is generally weak, mainly due to low-reflectivity of lower crustal material and attenuation of the seismic signal with propagation time. In order to analyze the SNR improvement via true-amplitude stacking, the following trace model is defined.

$$
T_{i j}=\alpha_{j} s_{i j}+\beta_{j} n_{i j}
$$

where $T_{i j}$ : amplitude at $i$ th sample at $j$ th trace in a CDP gather.

$s_{i j}$ : signal in the $j$ th trace assumed to be stationary.

$n_{i j}:$ noise in the $j$ th trace assumed to be stationary.

$\alpha_{j}, \beta_{j}$ : scales controlling signal or noise amplitude, respectively, in the $j$ th trace.

Noise is assumed to be statistically independent between traces that have zero mean and variance $\sigma^{2}$, and it is also assumed to be independent of the signal. Furthermore, it is assumed that only the signal and noise strength vary within a CDP gather; but signal and noise statistical properties are identical.

The $S N R$ after $N$-trace stacking is given by:

$$
S N R=\frac{S \sum_{j=1}^{N} \alpha_{j}}{\sigma \sqrt{\sum_{j=1}^{N} \beta_{j}^{2}}}
$$

where $S$ is the ensemble average of a signal or the amplitude of a signal. As mentioned in Robinson (1970), statistically optimum stacking can be achieved by equalizing the signal on each trace and weighting the resulting trace with the respective signal-to-noise ratio.

Here we studied $S N R$ improvement by an automatic trace editing quite similar to that of Mayrand and Milkereit (1988) and a weighted stacking similar to that of Robinson (1970).

\section{AUTOMATIC TRACE EDITING}

The main objective is to find a subset $N_{1}$ that improves the $S N R$ by $N_{1}$-trace stacking as compared with the straight $N$-trace stacking.

Using equation (2), we can define a modified $S N R,(S N R) *$ by:

$$
(S N R) *=\frac{S \sum_{j=1}^{N_{1}} \alpha_{j}}{\sigma \sqrt{\sum_{j=1}^{N_{1}} \beta_{j}^{2}}} .
$$

Then, we wish to find $N_{1}$ such that

$$
(S N R) *>(S N R)
$$


Mayrand and Milkereit (1988) proposed a method of searching $N_{1}$ by comparing the stacked traces generated by different subsets. Here, we investigated the range of the subsets that satisfy equation 4 under the following simple signal or noise model. Appendix 1 treats a more general trace model for $S N R$ improvement.

A. Signal model. - A signal model in a CDP gather is defined so that $N_{1}$ trace has identical signal strength $(S)$ and the remaining $N_{2}$ traces, $N_{2}=N-N_{1}$, have identical signals whose strength is scaled by $\alpha$ under the same ambient noise strength. In other words,

$$
\begin{aligned}
T_{i j} & =s_{i j}+n_{i j} \text { (for) } j=1,2 \ldots N_{1} \text { (reference traces) } \\
& =\alpha s_{i j}+n_{i j} \text { (for) } j=N_{1}+1, \ldots N .
\end{aligned}
$$

In this signal model, equation 4 can be written as:

$$
\frac{S\left(N_{1}+N_{2} \alpha\right)}{\sigma \sqrt{N}}<\frac{S}{\sigma} \sqrt{N_{1}}
$$

The solution of equation $6, \alpha_{c}$, is given by:

$$
\begin{aligned}
& 0<\alpha_{c}<\frac{1}{q}(\sqrt{1+q}-1), \\
& \text { where } \quad q=\frac{N_{2}}{N_{1}} .
\end{aligned}
$$

In other words, under constant ambient noise, rejecting the trace that has signal strength less than $\frac{1}{q}(\sqrt{1+q}-1)$ of the reference signal will improve $S N R$ during the stacking process.

B. Noise model.-Likewise, the noise model is defined by:

$$
\begin{aligned}
T_{i j} & =s_{i j}+n_{i j} \text { for } j=1, \ldots N_{1} \\
& =s_{i j}+\beta n_{i j} \text { for } j=N_{1}+1, \ldots N
\end{aligned}
$$

In this case, equation 4 can be written as

$$
\frac{S N}{\sigma \sqrt{N_{1}+N_{2} \beta^{2}}}<\frac{S}{\sigma} \sqrt{N_{1}}
$$

and its solution, $\beta_{c}$, is given by

$$
\beta_{c}<\sqrt{2+q} .
$$

Equation 9 indicates that dropping the traces that contain noise strength greater than $\beta_{c}$ of the reference trace will increase $S N R$ more than the straight $N$-trace stacking.

As shown in equations 7 and 9 , the $S N R$ improvement by dropping traces is a function of $q$, which is the ratio of number of rejected traces to number of retained traces during stacking. This analysis indicates that by dropping either the high noise trace (such as a noise burst) or the low-level trace (such as a weak source), or both, always increases the $S N R$. The range of the signal-to-noise ratio improvement will be discussed later.

\section{WEIGHTED STACK}

Now consider the $S N R$ improvement for the weighted stack under the same model conditions shown in equation 1. Using equations 1 and 2 , the $S N R$ for a weighted stack can be written as:

$$
(S N R) *=\frac{S \sum_{j=1}^{N} w_{j} \alpha_{j}}{\sigma \sqrt{\sum_{j=1}^{N} w_{j}^{2} \beta_{j}^{2}}},
$$

where $w_{j}$ is a weighting function for $j$ th trace such that

$$
\begin{aligned}
& w_{j}=1 \text { for } j=1,2 \ldots N_{1} \\
& w_{j}=w \text { for } j=N_{1}+1 \ldots N_{2} .
\end{aligned}
$$

A. Signal model.- In the case of varying signal strength with constant ambient noise (equation 5), the condition for $S N R$ of weighted stack is greater than the straight stack and is given by:

$$
\frac{1+q \alpha}{\sqrt{1+q}}<\frac{1+\alpha q w}{\sqrt{1+w^{2} q}}
$$

One of the choices for the weight function can be derived by requiring the ensemble average of trace energy to be equal among a CDP gather. This choice of weight is given by: 


$$
w=\sqrt{\frac{1+\gamma^{2}}{\alpha^{2}+\gamma^{2} \beta^{2}}},
$$

where $\gamma=\sigma / S$, the inverse of amplitude $S N R$ for the reference trace. With a choice of $w$ given in equation 11 with $\beta=1$, it can be shown that there is no solution for equation 10. This observation implies that in the signal model, weighted stack does not improve $S N R$ but rather degrades $S N R$.

B. Noise model.-When the noise strength changes while the signal strength remains constant in a gather, the condition of the $S N R$ of the weighted stack is greater than the straight stack given by:

$$
\frac{1+q}{\sqrt{1+q \beta^{2}}}<\frac{1+w q}{\sqrt{1+w^{2} \beta^{2} q}}
$$

The solution of equation $12, \beta_{c}$, can be written as:

When $w_{j}>1$

$$
\beta_{c}=\sqrt{\frac{q w+q+2}{2 q w+w+1}}<1
$$

and when $w_{j}<1$, then: $\beta_{c}>1$.

With this choice of $w_{j}$, given in equation 11 , the solution in equation 13 is an implicit relation between $\beta_{c}$ and $q$. It can be shown that the solution exists for all values of $\beta_{c}$. This means that the weighted stack always increases $S N R$ more than the straight stack when the signal strength is constant throughout the CDP gather under variable, ambient noise.

For the particular case in which $\alpha=\beta$, the statistically optimum stacking by Robinson (1970) is quite similar to this approach.

The general behavior of $S N R$ improvement by editing and weighting can be inferred from the behavior of a two-trace stacking. In the signal model, as shown in equation 7 , dropping the trace whose signal strength is approximately less than 0.5 of the reference signal strength will increase the $S N R$, whereas weighted stacking will degrade the $S N R$. The $S N R$ improvement by editing is about 30 percent when $\alpha=0.1$ and the $S N R$ improvement is independent of $S N R$ of the reference trace. In the noise model, the $S N R$ improvement can be analyzed by the $S N R$ improvement factor defined by the ratio of $S N R$ of the edited or weighted stack to the straight stack.
This relation can be written as:

$$
q_{e}=\frac{\sqrt{1+\beta^{2}}}{2}
$$

for edited stack,

and

$$
q_{w}=\frac{(1+w) \sqrt{1+\beta^{2}}}{2 \sqrt{1+w^{2} \beta^{2}}} \quad \text { for weighted stack. }
$$

As shown in equation 14, the $S N R$ improvement for editing is independent of the $S N R$ of the reference trace, whereas the $S N R$ improvement by weighting depends strongly on the $S N R$ of the reference trace.

The relationship given in equation 14 for $S N R$ improvement a of two-trace stack with various $S N R$ of the reference trace ranging from 10 to 0.1 is shown in figure 1. In a two-channel stacking, $S N R$ improvement by editing can be achieved when $\beta>\sqrt{3}$ and an increasing function of $\beta$ (curve a of fig. 1). When $\beta \geq 2.5$, the edited stack is always better than the weighted stack in the $S N R$ range of 10-0.1. This observation is important in processing very noisy deep crustal data where $S N R$ is generally small. Also, $S N R$ improvement by weighted stacking is better for low $S N R$ than high $S N R$ data.

\section{SEISMIC DATA}

About 1,350 km of GLIMPCE seismic data were acquired during September 1986 with the objectives of better understanding the deep structure and tectonics of the Midcontinent rift system and the Grenville tectonic province (fig. 2). The energy was a 127.5-L $\left(7,780-\mathrm{in}^{3}\right)$ tuned airgun array, and 20 seconds of data were recorded by a 120-channel streamer. Detailed descriptions of data acquisition and data processing with an AGC application are found in Lee and others (1988). Some of the geological interpretations of this data set are in Behrendt and others (1988) for deep crustal structure of the Midcontinent rift system, Green and others (1988) for Grenville tectonics, and Cannon and others (1989) for detailed rift structure.

Most of the GLIMPCE data were shot in shallow water underlain by variable thicknesses of glacial deposits and Precambrian clastic, volcanic, or crystalline bedrock, resulting in contamination by abundant multiples and side-scattering noise. This paper does not address methods of suppressing coherent noise and these noises have been eliminated as much as possible prior to TA processing. 


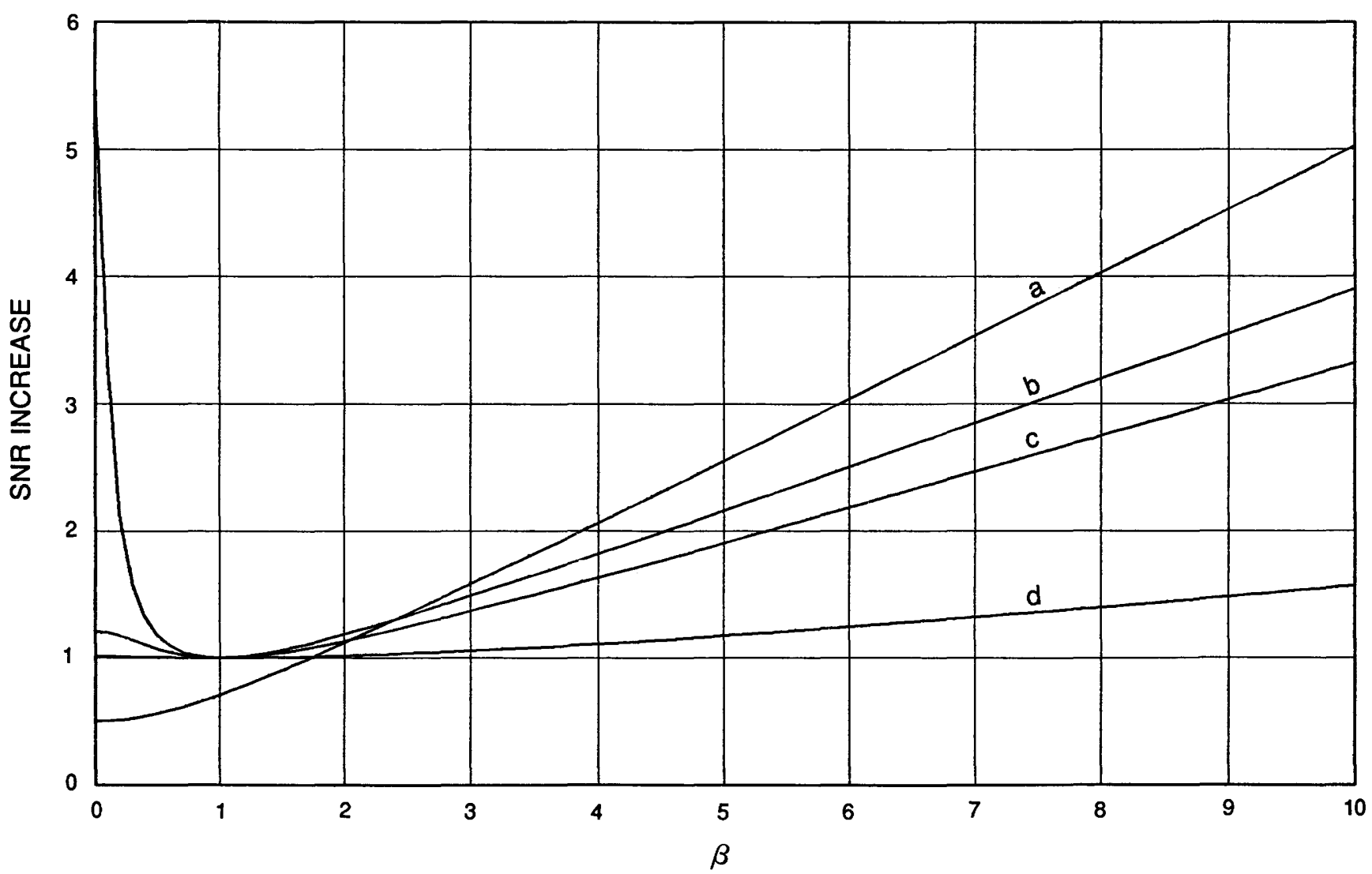

Figure 1. Signal-to-noise ratio $(S N R)$ improvement by an edited and weighted stacking for two-channel noise model. $\beta$ controls the amount of noise content, and $\gamma$ is the inverse of amplitude $S N R . \beta=1$ is a reference trace model, and increasing $\beta$ indicates increasing noise. a, Edited stacking; b, weighted stack with $\gamma=10$ (low $S N R$ ); $c$, weighted stack with $\gamma=1$; , weighted stack with $\gamma=0.1$ (high $S N R$ ).

All the data were processed at 24- and 30-fold (for shots spaced at 62.5 and $50 \mathrm{~m}$, respectively), and four adjacent traces were vertically summed resulting in a 50-m CDP interval.

\section{TRUE-AMPLITUDE PROCESSING}

Seismic amplitude decays with increasing recording time due to geometrical spreading, attenuation (a combination of intrinsic and apparent attenuation), and other propagation effects. Also, seismic amplitude varies laterally owing to the recording conditions in addition to the geological causes. The purpose of TA processing is to preserve the amplitude variation vertically as well as horizontally. In this paper, we focus on how to reduce the amplitude artifacts due to source or recording conditions and increased $S N R$. In order to preserve the vertical variation of relative amplitude, the amplitude decay should be corrected in a systematic manner. The generally accepted power law was applied to the GLIMPCE seismic data in order to correct this ampli- tude decay. The gain function we chose is a second power of two-way traveltime and was applied up to 18 seconds of two-way traveltime.

Generally, the lateral variation of deep reflections can be caused by the following reasons:

1. Changes in source strength and source coupling,

2. Changes in receiver coupling or recording condition,

3. Near-surface inhomogeneity such as shoals or channels,

4. Changes in noise levels,

5. Different propagation and attenuation properties of the inhomogeneous upper crustal material, and

6. Lateral lithologic changes of deep reflectors.

Even though the relative contribution of items 16 depends highly on local geology and can vary significantly from data set to data set, the purpose of true-amplitude processing is to preserve lateral lithologic changes (6) as much as possible.

In order to do a comparative study for TA 


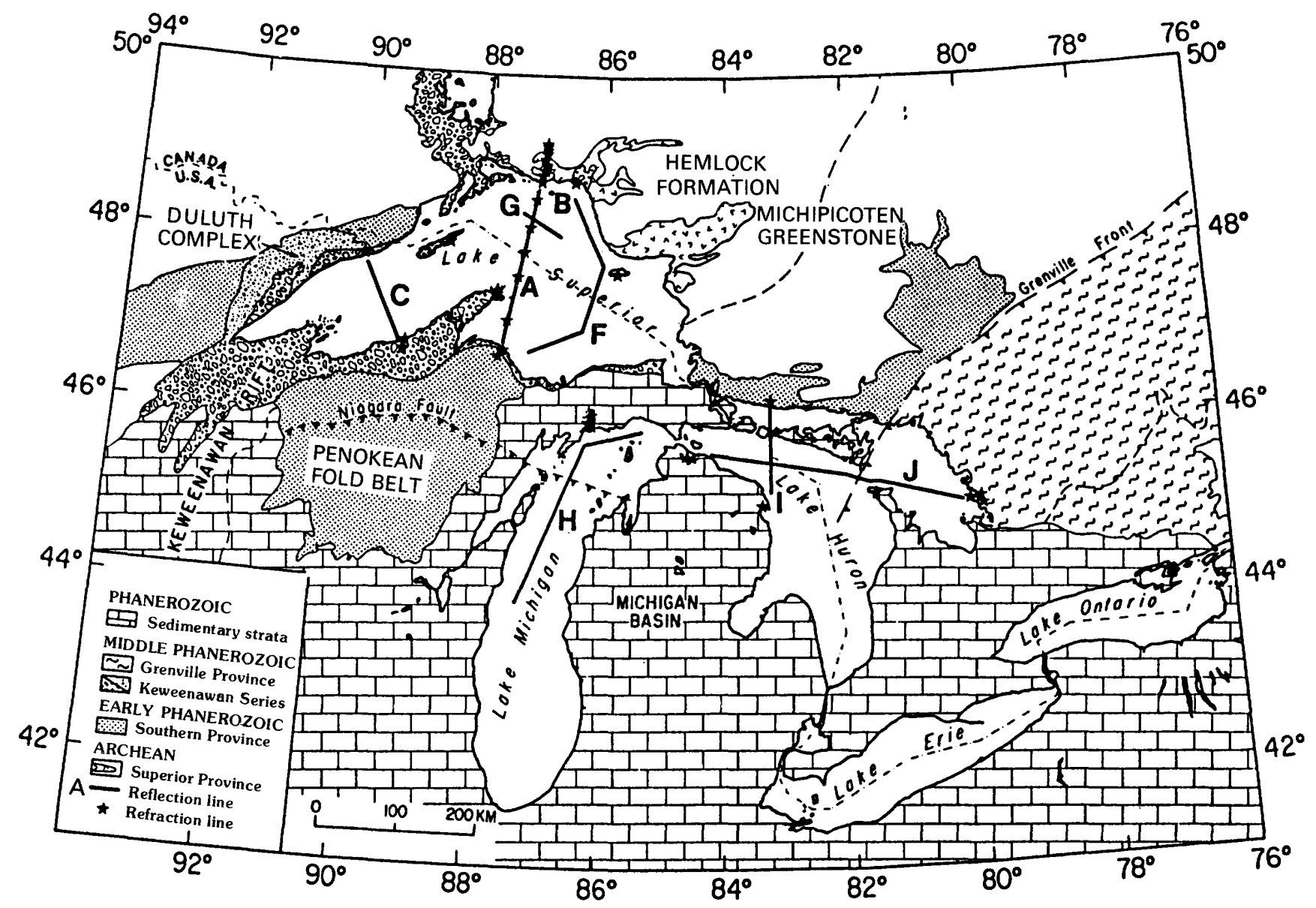

Figure 2. Location of GLIMPCE (Great Lakes Multidisciplinary Program on Crustal Evolution) seismic reflection lines (A-C, F-J, 1986) on a simplified geological map of the Great Lakes area, U.S.A.

processing techniques, we attempted the following three methods:

1. Automatic editing based on a median root-meansquare (RMS) amplitude in a CDP gather,

2. Single-trace RMS amplitude equalization, and

3. A CDP-gather RMS amplitude equalization.

Let's define RMS amplitude $A_{j}$ for the $j$-channel for a given time window as:

$$
\begin{aligned}
A_{j} & =\sqrt{\frac{\sum_{i=I_{1}}^{I_{2}} T_{i j}^{2}}{\left(I_{2}-I_{1}+1\right)}} \\
\text { for } i & =I_{1}, I_{1}+1, \ldots I_{2} \\
j & =1,2, \ldots N
\end{aligned}
$$

with $T_{i j}$ as the $i$ th sample of $j$ th trace in a CDP gather and $I_{1}$ and $I_{2}$ as the starting and ending time window.

Automatic editing procedure for TA processing is defined here as such that traces whose RMS amplitude does not satisfy the following relationship are omitted during the stacking. The condition is:

$$
C_{1} A_{m}<A_{j}<C_{2} A_{m}
$$

where $A_{m}$ is the median RMS amplitude in a CDP gather and $C_{1}$ and $C_{2}$ are lower and upper threshold constants, respectively. Consider the time window as an important parameter. For example, if the RMS amplitude analysis is done for the ambient noise part such as the time window before the first arrival or later part of the records for the deep crustal study, then we can choose $C_{1}=0$ and $C_{2}$ as a non-zero constant, depending on the data set. This case is similar to the noise model discussed in the earlier section, in which we edited out high ambient noise for TA processing. However, if the window is designed for the signal part, 
for example the first arrivals, we can select $C_{1}$ as some non-zero constant and $C_{2}$ as a large number. This method is similar to that of the signal model discussed earlier in which low-signal traces are edited out for TA processing. If the window contains both the signal part and noise part, we can use non-zero constants of $C_{1}$ and $C_{2}$.

If the trace model discussed previously (equations 5 and 8) can be applied to the median amplitudebased automatic editing procedure, we can write the automatic editing procedures using equations 7 and 9 as:

$$
\frac{1}{q}(\sqrt{1+q}-1) A_{m} \leq A_{j} \leq \sqrt{2+q} A_{m},
$$

and when $q$ is quite small, it can be approximated by

$$
\left(0.5-\frac{q}{8}\right) A_{m} \leq A_{j} \leq \sqrt{2\left(1+\frac{q}{4}\right) A_{m}} .
$$

The justification of the editing based on the RMS amplitude is as follows. One basic assumption for this approach is that the time average of seismic traces is close to the ensemble averages of the seismic traces. In other words, $A_{j}$ is close to the ensemble average of the trace model shown in equation 1. Lee (1960) provided an excellent discussion on the justification for the interchange of time and ensemble averages, and Robinson (1970) used this property for his investigation of optimum stacking.

Thus, for the purpose of automatic editing, we treat the median RMS amplitude $A_{m}$ as the ensemble average of a reference trace model shown in equation 5 or equation 8 . Therefore, under the assumption of small $q$, dropping the traces whose amplitude is approximately less than $0.5 A_{m}$ corresponds to editing out low-signal components in a CDP gather, possibly caused by a weak source strength. Also, dropping the traces whose amplitude is approximately greater than $\sqrt{2} A_{m}$ corresponds to editing out the high-noise component in a CDP gather such as a noise burst. Suppressing the high noise component of the data is the most important procedure in removing the outliers (high episodic random noise burst) in TA processing.

In summary, in the automatic editing method, lateral amplitude preservation will be accomplished through the assumption that the median RMS amplitude in a CDP gather is not affected significantly by the source (or recording) condition, noise contamination, or near-surface inhomogeneity; and $S N R$ will improve through dropping out high-noise and low-signal traces.

An example of TA processing of GLIMPCE line C in Lake Superior by the automatic editing procedure is shown in figure 3 . One part (fig. $3 A$ ) shows the stacked profile without any editing and the other (fig. $3 B$ ) shows the same section after the automatic editing procedure $\left(C_{1}=0.5, C_{2}=1.45\right)$, and a time window of 8-14 s. During this editing, a total of about 15 percent of the traces were edited out. A noise burst $(N B)$ in figure $3 A$ has been mostly removed after editing. This kind of NB problem is a common nuisance to all TA processing techniques to a varying degree. Figure $3 B$ indicates the $S N R$ improvement and the better lateral continuity of the reflections, although subtle, by the automatic editing procedure.

The RMS amplitude variation with two-way traveltime for differently stacked traces is shown in figure 4. In this example, the RMS amplitude was computed using a window of $40 \mathrm{~ms}$ and applying a five-sample median filter (200 ms) before plotting. The heavy line in figure $4 A$ represents the RMS amplitude of trace 60 shown in figure $3 A$ (no edit), and the light line represents the RMS amplitude of trace 60 in figure $3 B$ (edit). Also, the light line near $0 \mathrm{~dB}$ (decibel) represents the amplitude difference between the heavy and light RMS amplitude curve. Figure $4 B$ shows the same result except that the editing was done using $C_{1}=0.5$ and $C_{2}=2.0$.

Some interesting observations can be made from data shown in figures 3 and 4 :

1. The positive large difference (on the order of $10 \mathrm{~dB}$ ) before the onset time on figure $3 A$ indicates that automatic edit using $C_{2}=1.45$ reduced the ambient noise level quite a lot.

2. The negative difference on the order of $3 \mathrm{~dB}$ between 11 13 seconds in figure $4 A$ implies the signal enhancement of deep reflections, which occurs in the vicinity of the crust-mantle transition described by Behrendt and others (1988).

3. These empirical results confirm the theoretical prediction that $S N R$ improves by editing. They also support the prediction of $C_{2} \approx \sqrt{2}$ for small $q$.

4. In general, $S N R$ improvement increases with increasing time. This observation also confirms the previous analysis that the $S N R$ improvement by editing is greater for large noise content, because $S N R$ is decreasing with increasing traveltime.

In addition to the overall $S N R$ improvement, the amplitude increase on the order of $3 \mathrm{~dB}$ for the crust-mantle transition zone (shown as $\mathrm{E}_{1}$ and $\mathrm{E}_{2}$ in figure $4 A$ could be significant for quantitative analysis of the origin of deep reflections. We emphasize that the preceding observations and remarks will vary from data set to data set. However, the general behavior of automatic editing procedure based on simple noise or signal model is established. 

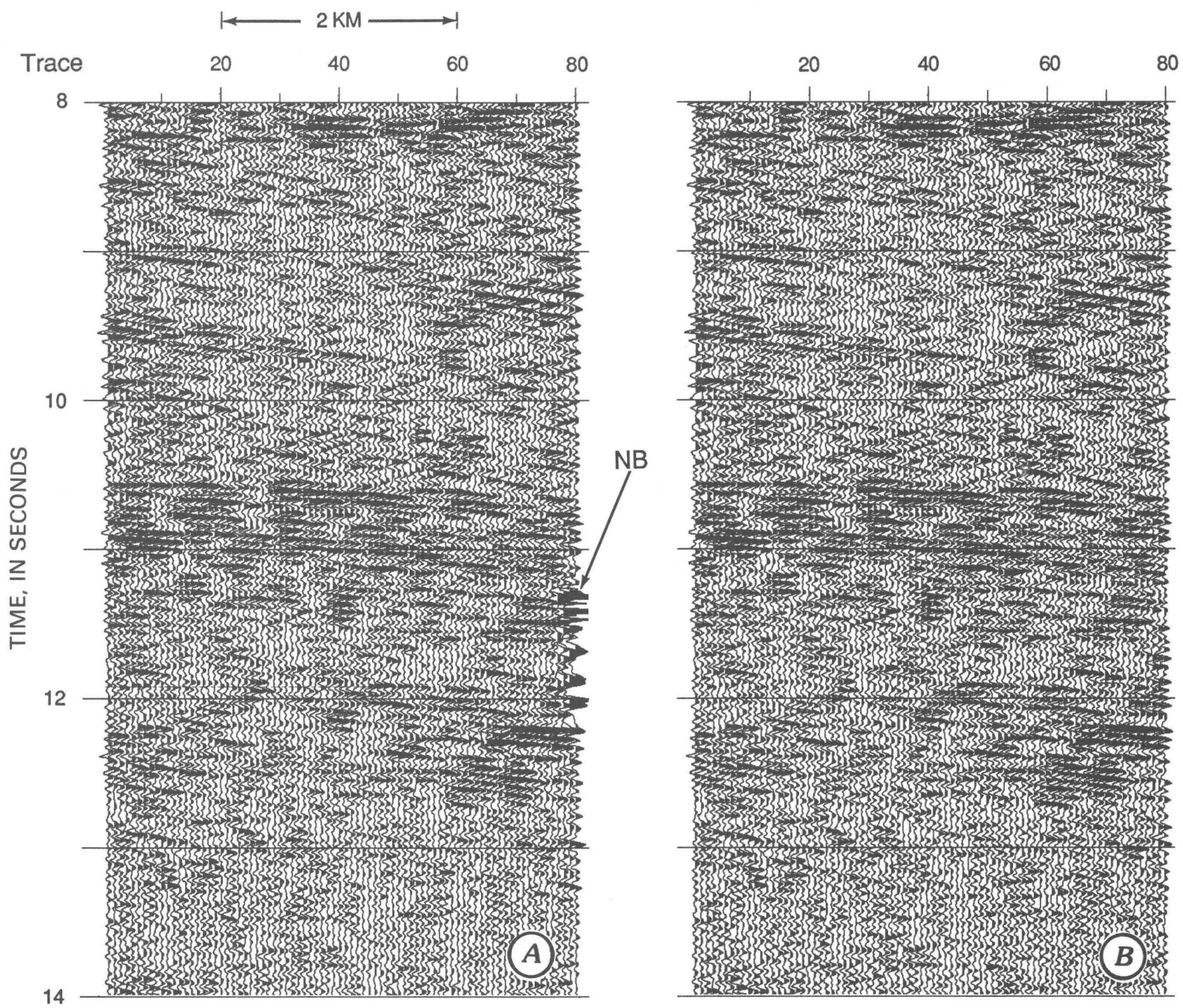

Figure 3. A comparison of true-amplitude processing. $A$, Processing without automatic editing; $B$, processing with automatic editịng. Editing parameters are $C_{1}=0.5, C_{2}=1.45$, and 8-14 seconds time window. $\mathrm{KM}$, kilometer; NB, noise burst.

Also, TA processing by editing the traces as described is not an optimum processing method as far as $S N R$ improvement is concerned. The $S N R$ improvement by editing depends highly on the threshold constants $\alpha_{c}$ or $\beta_{c}$. Because the noise or signal statistics of the real data in a CDP gather is much more complex than the simple model shown in equation 1 and the trace statistics vary among CDP gathers, the optimum selection of $\alpha_{c}$ or $\beta_{c}$ cannot be achieved unless some trial-and-error method is performed at every CDP gather. Our methods simply illustrate that the $S N R$ improves by either editing out low-signal or high-noise traces.
Single-trace RMS amplitude balancing can be done by replacing $T_{i j}$ by $\tilde{T}_{i j}$, which is given by:

$$
\tilde{T}_{i j}=\frac{R}{A_{j}} T_{i j}
$$

where $R$ is some reference amplitude.

If the ensemble average of a trace is very close to time average, $\frac{R}{A_{j}}$ is similar to the weighting factor defined in equation 11. This process is similar to windowed-trace equalization by Yu (1985). The basic assumption of our single-trace balancing method is that 


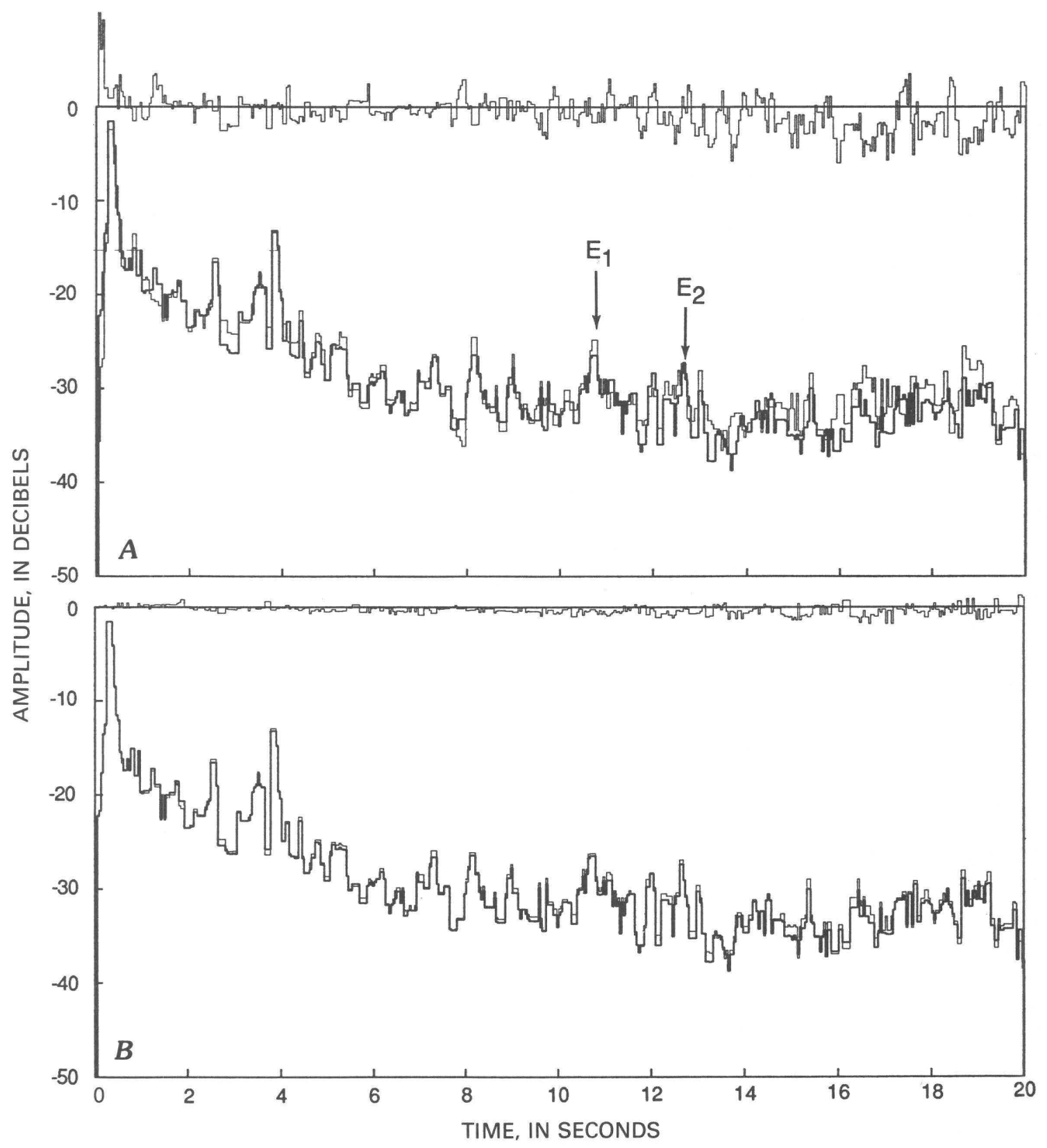

Figure 4. Comparison of vertical amplitude variation of true-amplitude-processed traces. Heavy line indicates root-mean-square amplitude without editing, and light line indicates root-mean-square amplitude with editing. Light line near 0 decibel denotes amplitude differences between heavy and light lines. $A$, Editing with $C_{1}=0.5$, $C_{2}=1.45$, and 8-14 seconds time window; $B$, editing with $C_{1}=0.5, C_{2}=2.0$, and 8-14 seconds time window. $E_{1}$ and $E_{2}$ represent large amplitude reflections in the lower crust.

the effect of amplitude variation in a CDP gather caused by non-geological effect can be suppressed by balancing the RMS amplitude of each trace.

$S N R$ improvement of single-trace RMS equalization can be analyzed based on $S N R$ improvement of the weighted stack mentioned previously. If the signal strength is somewhat constant in a gather and noise strength varies among the traces, single-trace RMS equalization always improves $S N R$ compared to the straight stack. On the other hand, when signal strength changes in uniform ambient noise level, this process always degrades $S N R$. If the RMS amplitude level within a given time window is constant in all traces, irrespective of source or receiver location, this process could 
also preserve the lateral amplitude variation.

The third method, which uses the RMS amplitude equalization of a CDP gather, is considered in an attempt to preserve the lateral amplitude variation. The method replaces $T_{i j}$ by $\tilde{T}_{i j}$, that is:

$$
\begin{aligned}
\tilde{T}_{i j} & =\frac{R}{A} T_{i j} \\
\text { where } \quad A & =\frac{1}{N} \sum_{j=1}^{N} A_{j},
\end{aligned}
$$

and $R$ is constant.

As can be seen from equation 19, there is no $S N R$ improvement during stacking (same as the straight sum), but the RMS amplitude level between stack traces is somewhat balanced. The idea behind this approach is the assumption that the average total power of a CDP gather in a given large time window is constant if there is no change in recording or source conditions.

\section{COMPARISON OF THE METHODS}

The TA stacked section of a part of line A (reflection line A on figure 2) with an automatic edit is shown in figure $5 A$. Edit parameters are $C_{1}=0.5$, $C_{2}=2.0$, and 8-14 s time window. The choice of $C_{2}=2.0$ is conservative and is chosen mainly to remove the effect of high-amplitude noise burst. Amplitude loss in the middle of the section (trace 50-80) below 4-5 s is accompanied by high-amplitude coherent noise in the top $0-4 \mathrm{~s}$ that is possibly caused from the irregular water bottom. For this dim zone, lateral changes in the strength and continuity of reflections below 4-5 s represents artifacts of near-surface noise effects rather than actual subsurface changes in the reflectivity.

The same result with a single-trace RMS amplitude equalization using a time window of $5-20 \mathrm{~s}$ is shown in figure $6 A$. Similar dim spots are observed, and the near-surface effect on the lateral continuity of reflections is more pronounced in figure $6 A$ than in figure $5 A$.

The stacked profile using a CDP-gather equalization and a time window of $8-20 \mathrm{~s}$ is shown in figure $7 \mathrm{~A}$. The result also shows a dim spot similar to that observed in figures $5 A$ and $6 A$. In addition to dim spots, figure $7 A$ shows the contamination of an outlier (shown as an arrow near trace 120). The whole trace shown by the arrow looks like a dead trace, but a large-scale plot indicates that this outlier is an isolated high-amplitude noise burst (amplitude highly reduced due to equalization) around $14 \mathrm{~s}$. This kind of noise presents a problem during the migration process, creating a migration smile. Also notice the reduced amplitude of the right-dipping events near $15 \mathrm{~s}$ compared with the events shown in figure $5 \mathrm{~A}$.

The dim spot below $4-5 \mathrm{~s}$ at traces $50-80$ is a typical example of deterioration of the lateral continuity of deep reflections owing to a dramatic change in $S N R$ caused by near-surface inhomogeneities. On the basis of the results of the three methods, we interpret that this abrupt $S N R$ change is due to both a loss of transmitted signal and an increase of coherent noise rather than to an increase of ambient noise level.

The vertical amplitude variation with time for four consecutive stacked traces of part of line $\mathrm{C}$ is shown in figure 8. Each dot represents each RMS amplitude computed within a 40-ms time window, and the solid line denotes five sample (200 ms) median RMS amplitudes of the mean of the four traces. The amplitude variation of a stacked trace using an automatic edit process and $C_{1}=0.5, C_{2}=2.0$, and 8-16 s time window is shown in figure $8 A$. The amplitude variation for a CDPgather equalization is shown in figure $8 B$. Both figures show a great deal of scattering, but their mean values of four consecutive traces are similar. Similar amplitude variations are observed for the single-trace RMS equalization method.

We examined about $700 \mathrm{~km}$ of TA-processed GLIMPCE data (lines A, C, and G, and part of lines F, $\mathrm{B}, \mathrm{H}$, and $\mathrm{J}$; see figure 2). The performance of the TA methods, on the basis of the 700-km GLIMPCE data, is as follows.

1. All three methods preserve the vertical amplitude variation except for a few traces contaminated by high-amplitude episodic events. For both amplitude equalization methods, the time window should be large in order to have better statistics, and the window should avoid upper crustal regions (approximately less than $5 \mathrm{~s}$ ) because of the significant lateral inhomogeneity of the upper crust and coherent noise contamination.

2. All three methods failed to preserve true lateralamplitude variation of deep reflections to a different degree and manner. The performance varies from line to line and from location to location. Generally, the failure to preserve lateral continuity comes from the data itself and not from the technique used. This conclusion necessitates a need for a post-stack amplitude adjustment.

3 . The automatic editing technique provides an overall $S N R$ improvement for the deep reflections (greater 

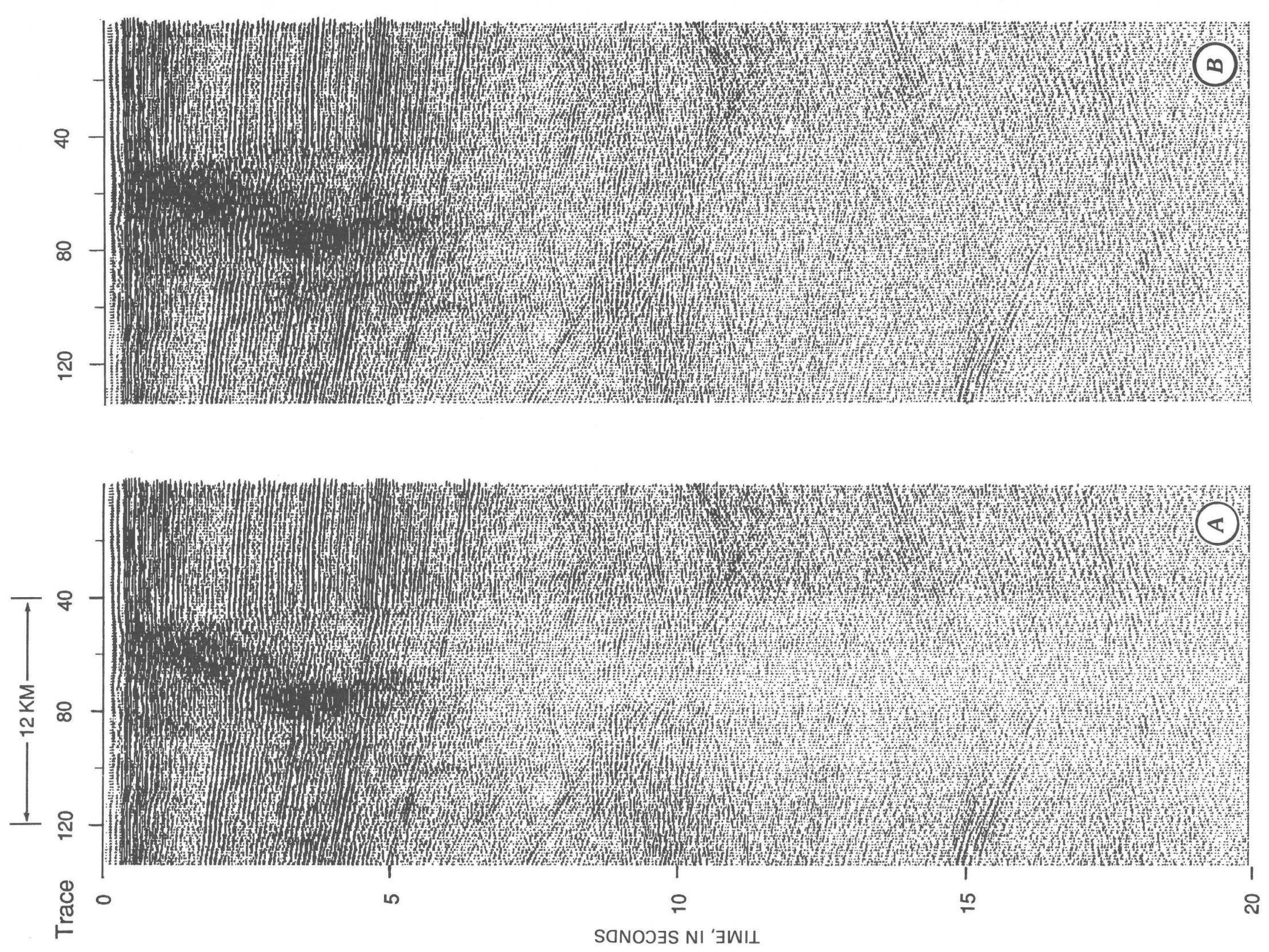

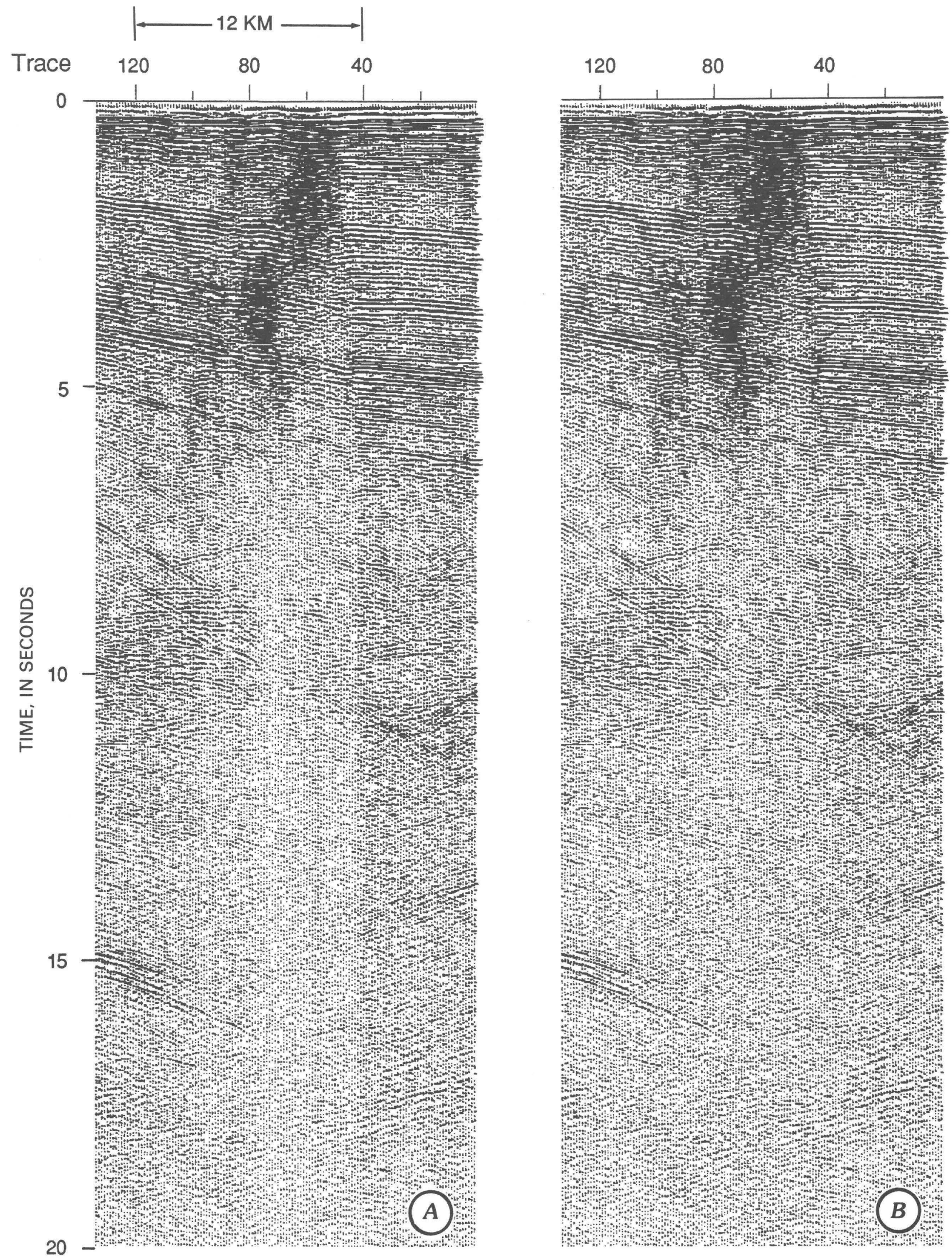

Figure 6. An example of true-amplitude processing for a part of line A (reflection line A on fig. 2; see same part of line on fig. 5) by a single-trace, root-mean-square equalization using 5-20 seconds time window. Every third trace was plotted for clarity. $A$, Without post-stack amplitude adjustment; $B$, with post-stack amplitude adjustment using $15-20$ seconds time window. KM, kilometer. 

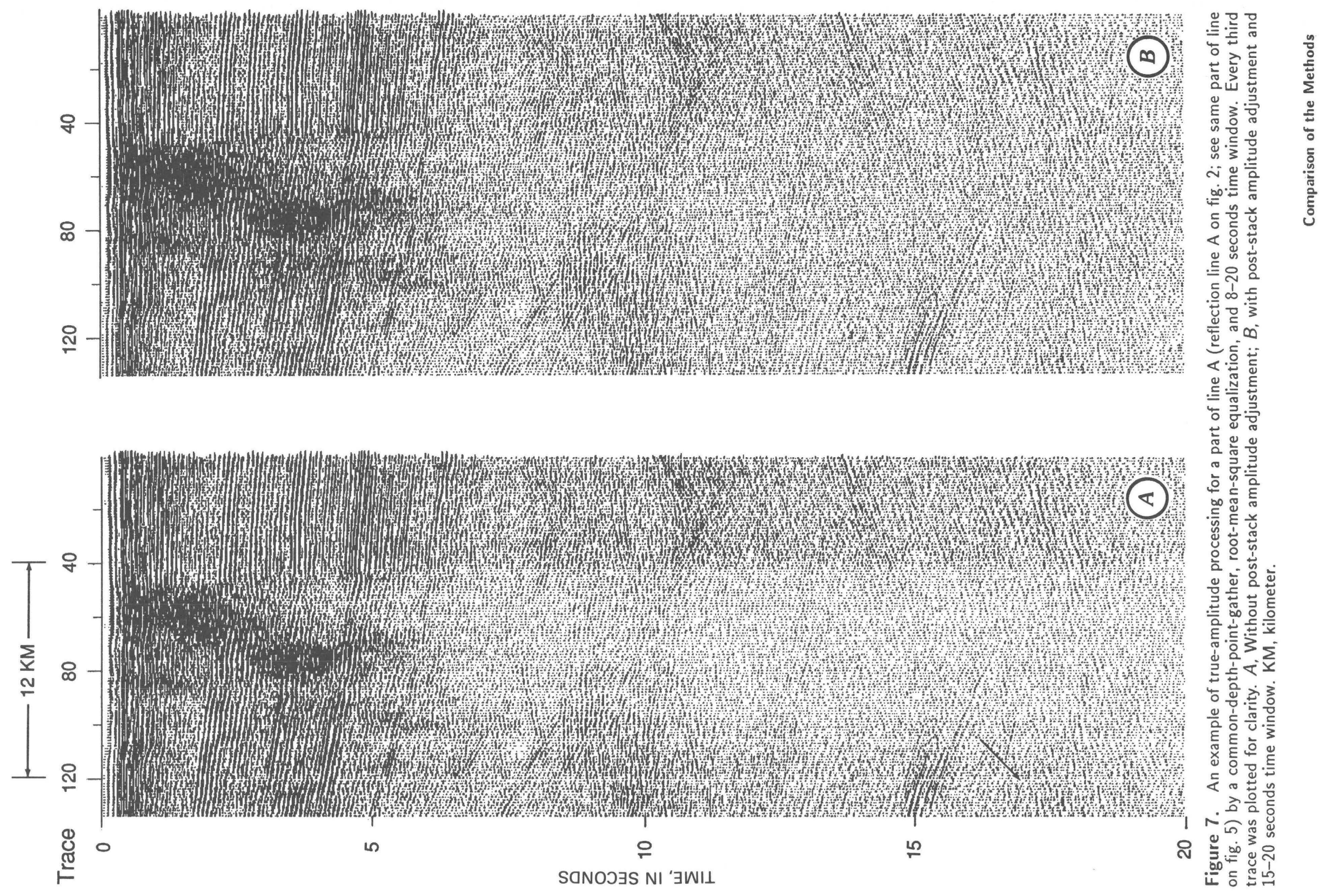


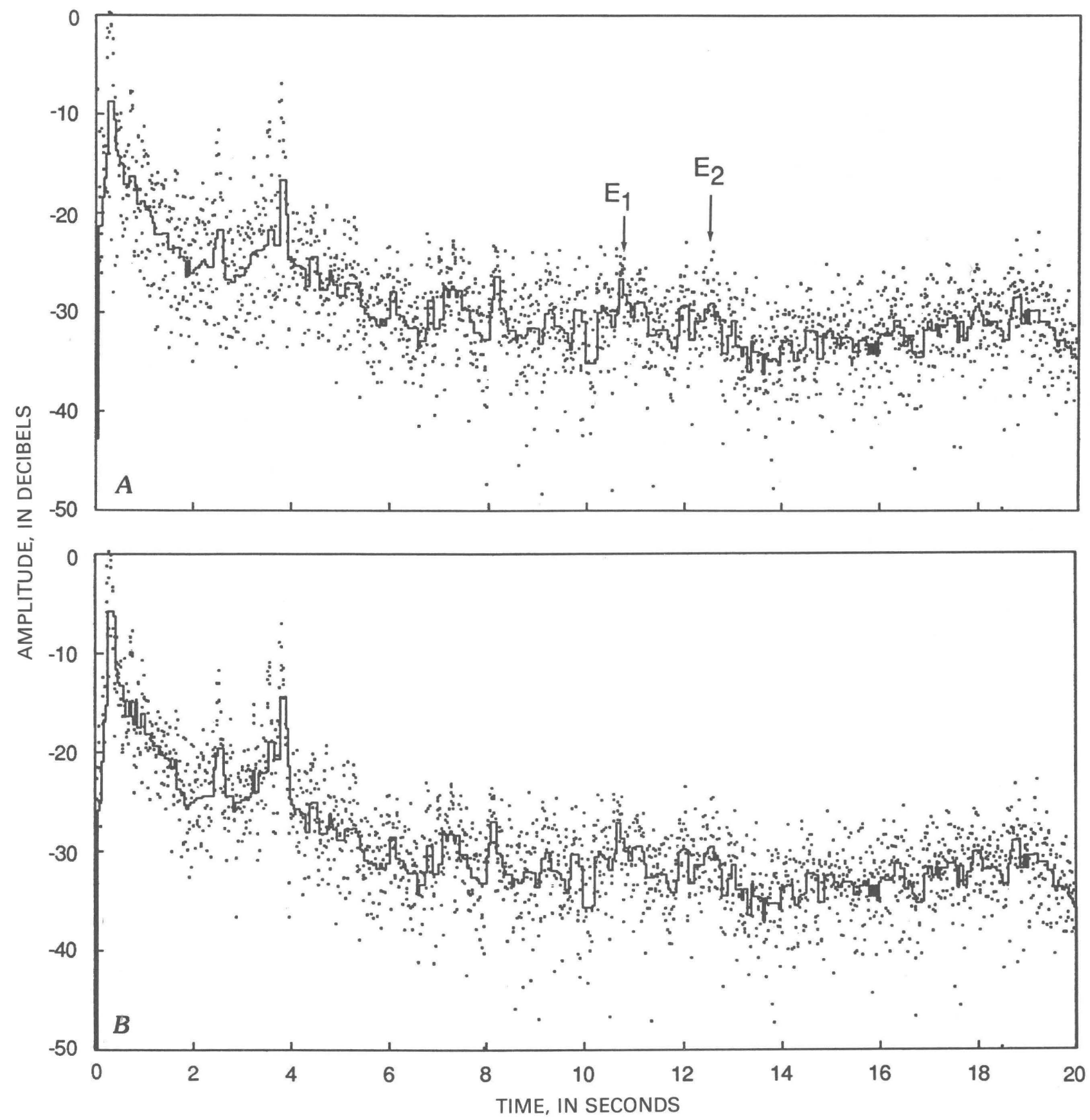

Figure 8. Comparison of vertical amplitude variation for true-amplitude (TA) processed traces. Each dot represents a rootmean-square (RMS) amplitude of 40-ms time window. Amplitudes of adjacent four traces are plotted. A solid line represents a five-sample median amplitude of a mean of the consecutive four traces. $A$, TA processing using an automatic edit; $B$, TA processing using a common-depth-point-gather RMS equalization. $E_{1}$ and $E_{2}$ represent large-amplitude reflections in the lower crust.

than approximately $8 \mathrm{~s}$ ), and a CDP-gather equalization presents more difficulties in handling outliers.

\section{POST-STACK ADJUSTMENT}

As observed previously, the lateral continuity of the deep reflections is difficult to preserve and the degree of lateral amplitude preservation is datadependent. During the GLIMPCE data acquisition, the 60-airgun array performed quite satisfactorily, and array volume was nearly constant throughout the survey. Also, there were no obvious problems related to the streamer except for the reduced buoyancy of 
the fresh water in the lakes. Thus, the lateral amplitude variation of the deep reflections, such as those shown in figures $5-7$, is probably not caused by changes in source strength or receiver coupling. We found three key elements for the deterioration of lateral continuity.

1. High impedance near surface inhomogeneities (such as channels and shoals) commonly prevents the transmission of seismic signal and generates abundant coherent noise. This kind of example is shown in figures $5 A, 6 A$, or $7 A$ near trace 60 . We call this a "type 1 " effect.

2. Substantial changes within the near-surface geology affect the transmission of the seismic signal dramatically ("type 2" effect). An example of this kind of problem is shown in figure 9. Cannon and others (1989) interpreted the Douglas fault, near trace 1200 in figure 9 , as a major fault bounding the rift basin within Lake Superior. The amplitude characteristics north of this fault are remarkably different from those south of it; notice how traces 400-1200 are dim relative to traces 1200-2180. The RMS amplitude within the upper $1 \mathrm{~s}$ does not change much across the fault. However, the RMS amplitude below $2-3 \mathrm{~s}$ has an average difference of about $10 \mathrm{~dB}$. This amplitude change across the fault is observed in the stacked traces by automatic editing, the median amplitude of the CDP gathers, and the near traces. For this problem (fig. 9), RMS amplitude equalization techniques worked better than the editing technique. We interpreted this amplitude variation to be caused by the changes of transmission characteristics of the shallow upper layers and not from changes in the data acquisition. This kind of lateral amplitude change should be corrected also.

3. Strong lateral heterogeneity of upper crustal material affects the amplitude of the deep reflections. The discontinuous appearance of deep reflections shown under the brace in figure 9 reflects the lateral heterogeneity of the upper crustal material. We call this propagation effect a "type 3 " effect.

The migration method partially corrects for type 3 effect, but type 1 and 2 effects should be corrected by some other method in order to investigate the deep reflections.

We propose an RMS amplitude adjustment after stack as a quick solution. The amplitude adjustment factor $(\delta)$ is defined as

$$
\delta=\frac{R}{A_{j}^{n}}
$$

where $R$ is a constant, $A_{j}$ is the RMS amplitude of the stacked trace within a specified time gate, and $n$ is an exponential constant that controls the degree of adjustment. Notice that this amplitude adjustment does not alter the vertical amplitude variation.

Figures $5 B, 6 B$, and $7 B$ show the after-stack amplitude adjustment of figures $5 A, 6 A$, and $7 A$, respectively, in which $n=1$ and time window is $15-20 \mathrm{~s}$. Without any doubt, post-stack amplitude adjustment produces a better and more geologically sound seismic section. Another advantage of post-stack amplitude adjustment can be found in the migration process. Warner (1987) mentioned some of the problems associated with migrating deep crustal seismic data, that is, synformal migration artifacts (smiles). He attributed most of the artifacts to an abrupt amplitude change caused by structures in the top few kilometers of the surface. Thus, balancing the amplitude variation in a reasonable way is important in order to reduce migration artifacts.

The result of migration of data stacked by an automatic edit without post-stack amplitude adjustment is shown in figure $10 A$, and the migration result with a post-stack amplitude adjustment is shown in figure $10 B$. Part of the unmigrated section is shown in figure 5. The result indicates that post-stack amplitude adjustment not only reduces migration noise but also increases overall $S N R$. Because migration artifacts tend to increase with increasing two-way traveltime, reducing abrupt lateral amplitude changes by post-stack amplitude adjustment is extremely important for imaging deep crustal reflections.

The selection for the post-stack RMS window is more critical than the pre-stack RMS window for TA processing. Our experience with the GLIMPCE seismic data indicates that the time window should not include the most heterogeneous upper crustal region (less than about $5 \mathrm{~s}$ ). The window that worked best was $15-20 \mathrm{~s}$, in which coherent back-scattering energy dominated the section.

\section{DISCUSSION}

Examples of TA-processed GLIMPCE deep crustal profiles using the automatic editing procedure are shown in figures 11 and 12 (line $\mathrm{C}$ and line A, fig. 2, respectively). We will not discuss the detailed geological implications of these profiles, but rather the TA techniques and the usefulness of TA processing for deep crustal study.

Post-stack amplitude adjustment was applied to both lines $\mathrm{C}$ and A (fig. 2) using a 15 - to 20 -s window. Neither line is migrated. Figure 9 is identical to figure 11 except that no post-stack amplitude adjustment has 


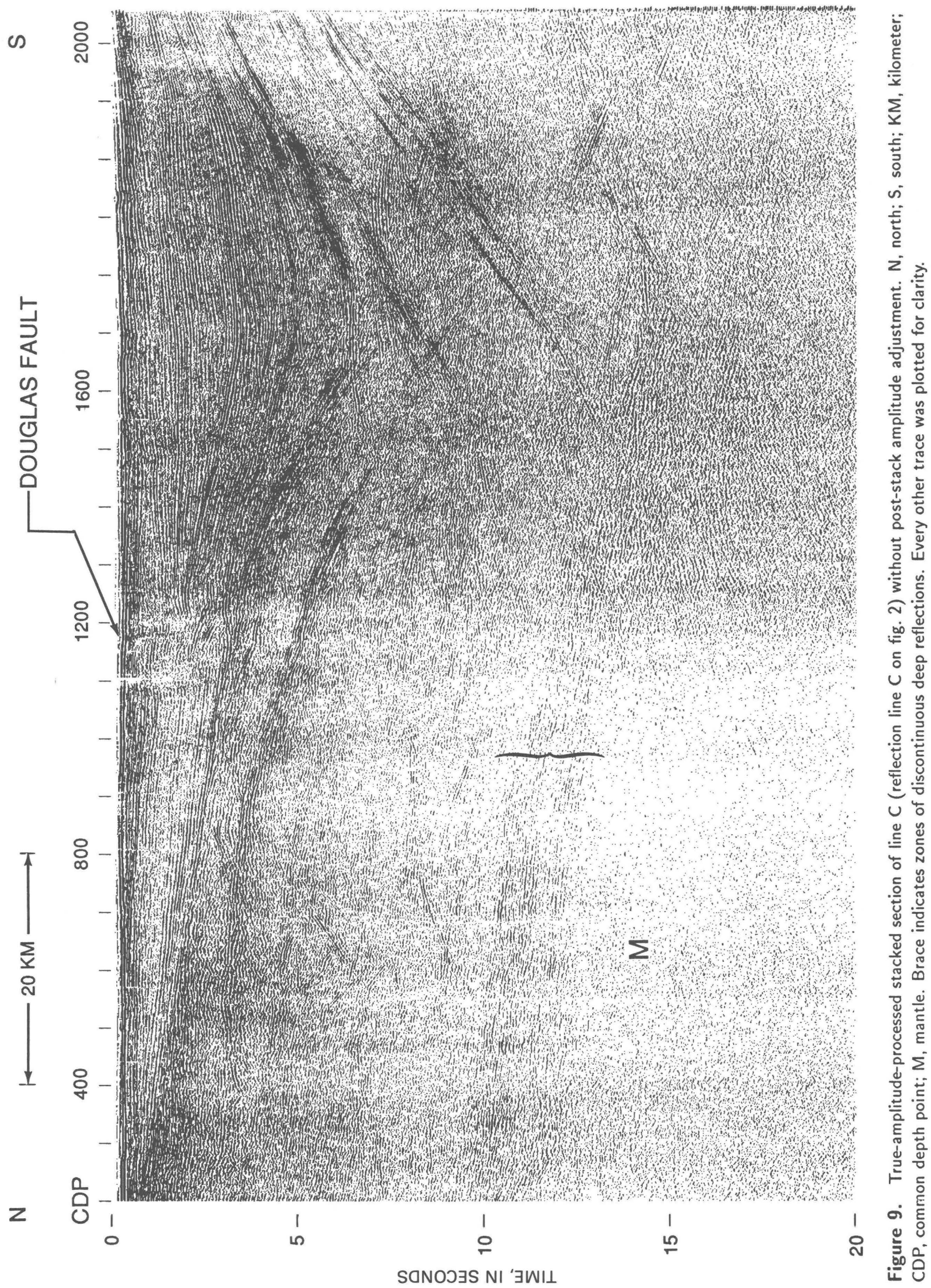



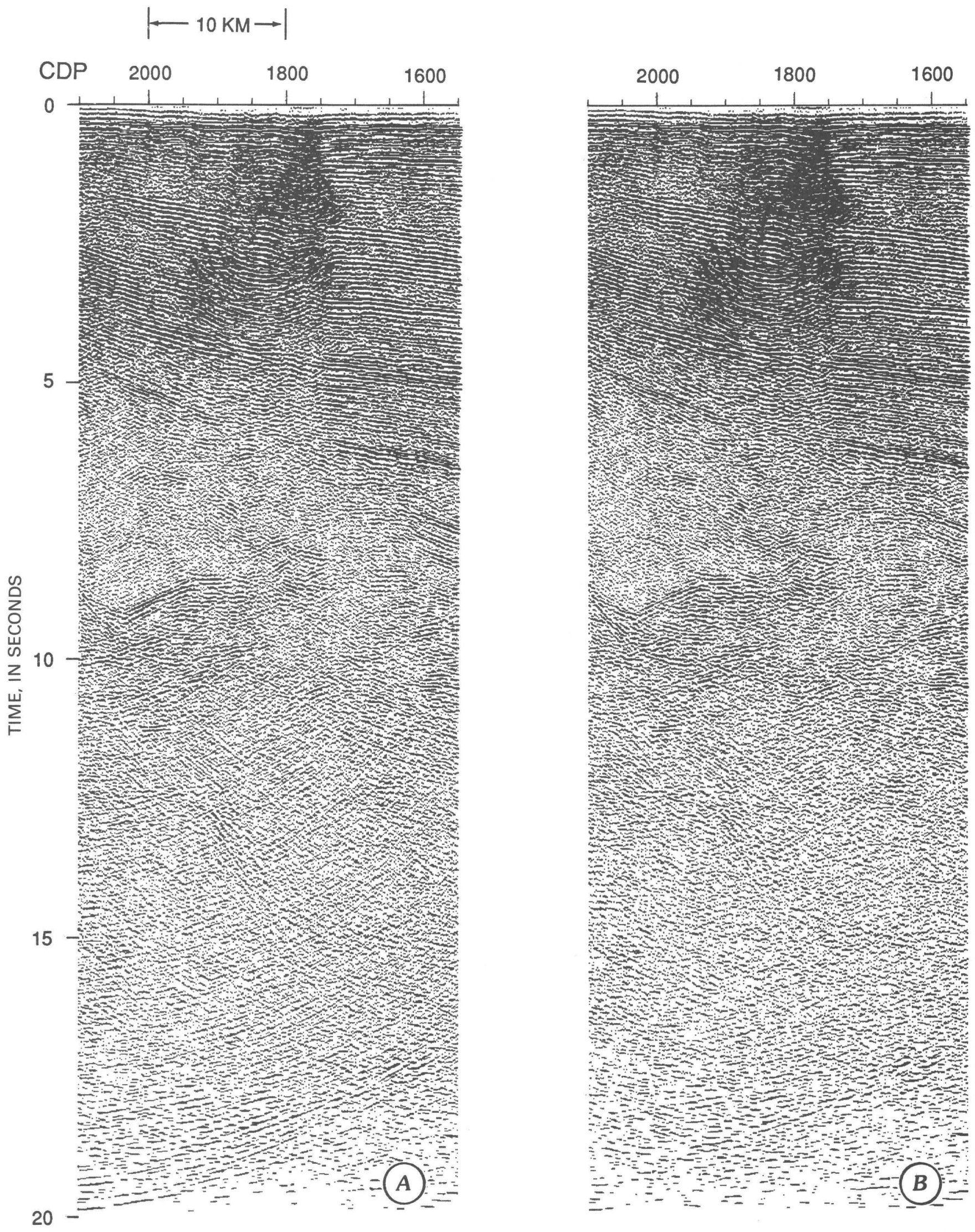

Figure 10. Comparison of migration result for true-amplitude-processed section for line $\mathrm{A}$ (reflection line A, fig. 2). A, Migration without post-stack amplitude adjustment; every fourth trace was plotted for clarity. $B$, Migration with post-stack amplitude adjustment. KM, kilometer; CDP, common depth point. 


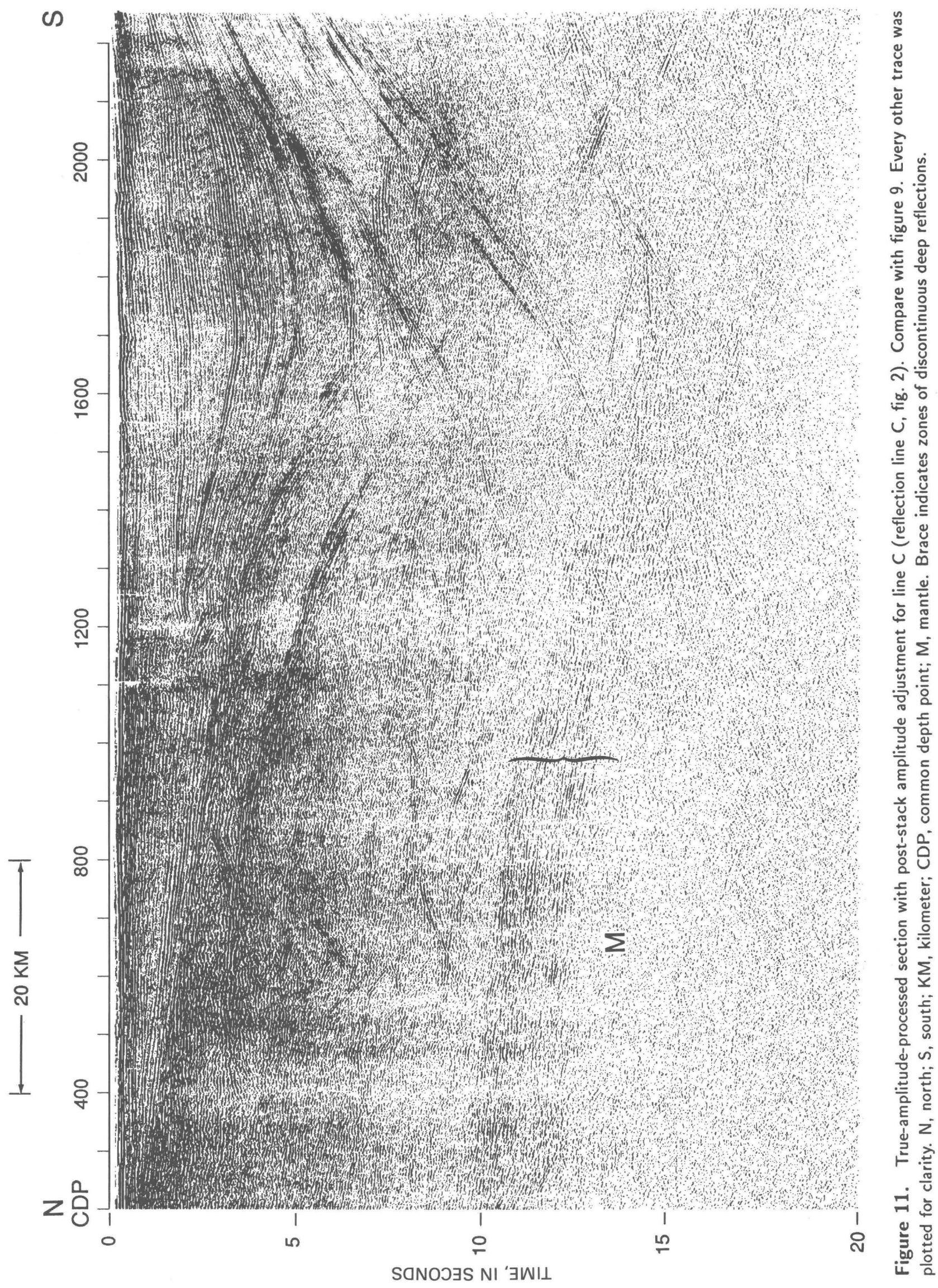




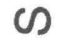

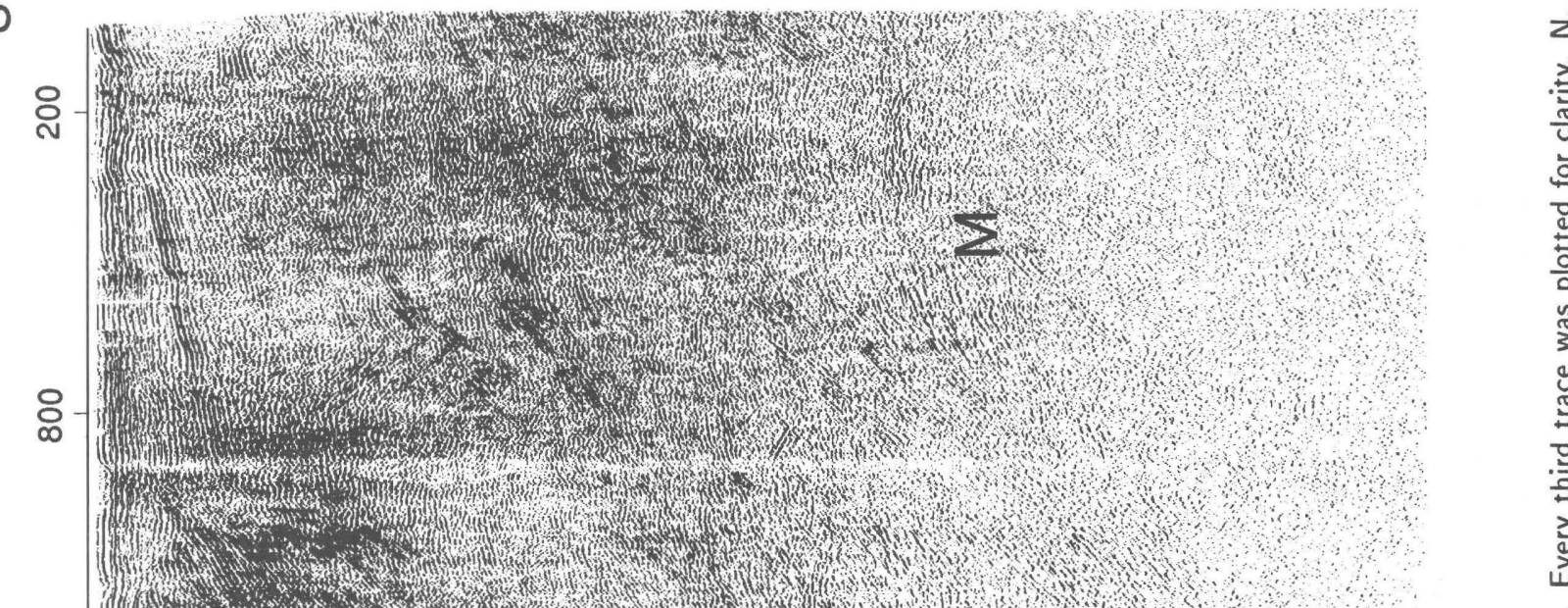

\&

20.7.

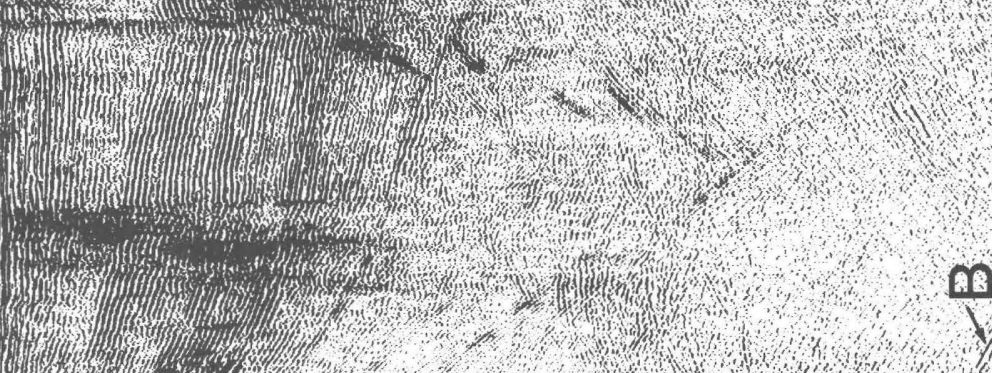

¿ั่

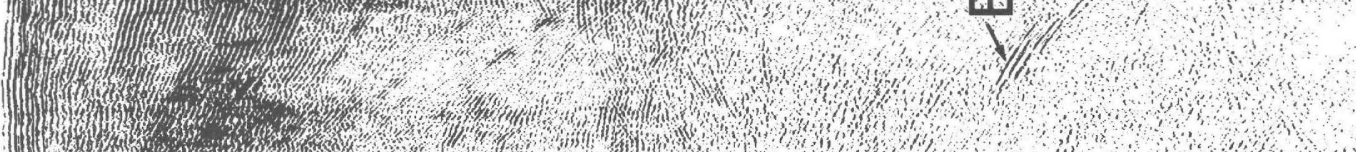

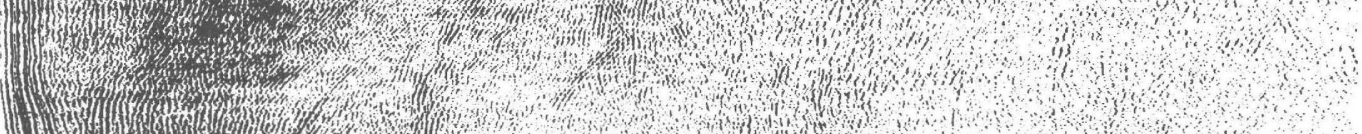

H.

H.

$\sum_{\Sigma}$

H

ֻ

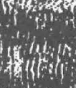

(H)

10.

్ㅡ-

1.

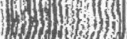

(1)

(1.).

1.7.2.

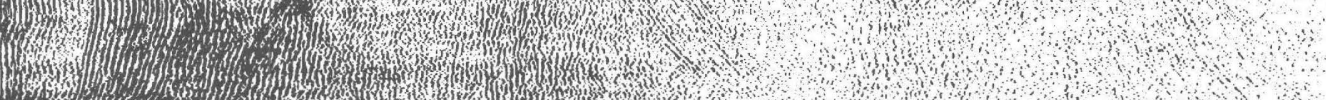

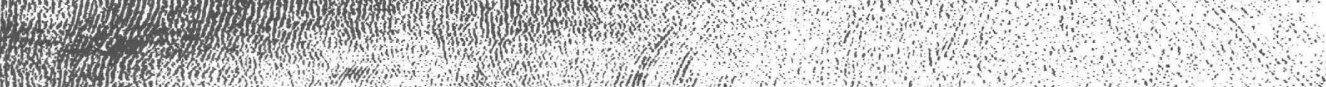

:

-

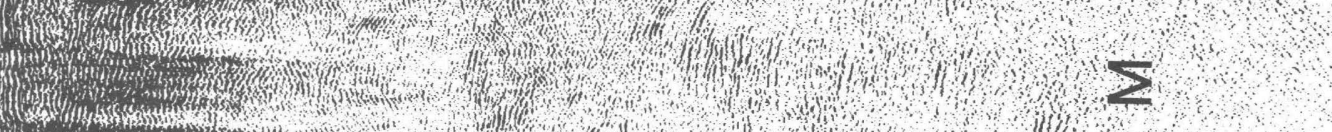

${ }_{2}$

H.

${ }_{3}^{3}=H_{2}$

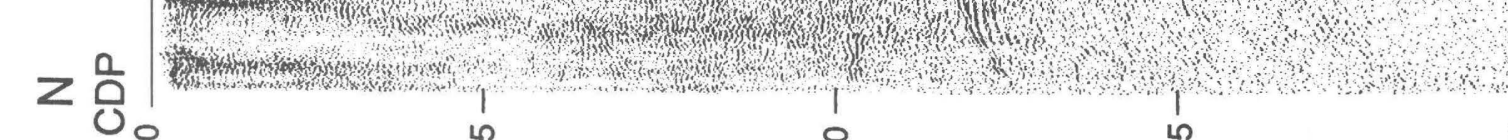

으

$\stackrel{20}{\circ}$

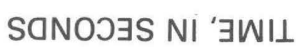

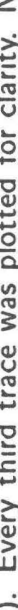

ก

禹

$<$

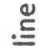

.$\overline{\frac{0}{*}}$

ֻ

$<$

.

ㅎํำ

들

约

总答

車

릉

弟

in

茖

है

은

约

ఫृ

ญํํㅇ

은

힣

븡 음

ह

峁

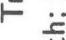

굼

is

总 
been applied. Comparing these two sections, we can conclude that post-stack amplitude adjustment compensated for the type 2 effect reasonably well. On the lower part of line $\mathrm{C}$, the dim zone from trace 4001200 in the section without post-stack amplitude adjustment (fig. 9) is nearly eliminated in the section with it (fig. 11). Some dim spots still remain throughout line $\mathrm{C}$ and are probably related to the type 3 effects - the propagation effect-rather than to the type 1 or type 2 effects.

The type 1 effect is easily recognized owing to its association with a localized and short duration (in the range of $5 \mathrm{~s}$ ) amplitude burst. Recognizing the type 2 effect, however, needs a detailed analysis. Only line $\mathrm{C}$ clearly shows the type 2 effect. All other lines are contaminated mostly by the type 1 effect.

Both figures 11 and 12 indicate that the proposed post-stack amplitude adjustment is not an ideal solution for preserving lateral continuity of deep reflections, but that it works reasonably well in reducing type 1 and 2 effects on the deep reflections.

One of the important aspects of the TA section is its ability to identify deep reflections based on the strength of the reflection in addition to lateral coherency. The banded reflections shown in figure 11 within the brackets lie above the inferred upper mantle ( $M$ in figure 11) and have been interpreted as reflections from the crust-mantle transition zone (Behrendt and others, 1988). The amplitude contrast shown in figure 11 and arrival times of these reflections support this interpretation quite well. Detailed vertical amplitude analysis shown in figure 8 indicates that an average amplitude of reflections within this zone is more than $6 \mathrm{~dB}$ higher than that of back-scattering noise in the upper mantle. The amplitude analysis indicates two distinct reflection arrivals ( $\mathrm{E}_{1}$ and $\mathrm{E}_{2}$ in figure 8), and these reflections are similar to the double band of reflections at the base of the crust noted elsewhere in the continental U.S. (Klemperer and others, 1986). The reflection strength of $\mathrm{E}_{1}$ or $\mathrm{E}_{2}$ can be estimated from the TA-processed section. On the basis of amplitude variation shown in figure 8 and water-bottom reflection coefficient (about 0.6), the reflection coefficient of the $\mathrm{E}_{1}$ and $\mathrm{E}_{2}$ reflections are estimated to be in the range of 0.05 . This reflection coefficient was estimated near CDP 890 shown in figure 11. This reflection strength is somewhat less than that calculated for bright spots within the crust (de Voogd and others, 1986) and upper mantle (Warner and McGeary, 1987). Reflection coefficients vary along the crustal-mantle transition and are estimated to be about 0.1 near CDP 700 of line C. These reflection coefficients, taken in conjunction with velocities determined from coincident refraction data recorded during the GLIMPCE experiment (fig. 2), will provide a critical constraint in interpreting possible lithologic boundaries at the crust-mantle transition.

In figure 12, $\mathrm{M}$ indicates reflections near the Moho discontinuity interpreted by Behrendt and others (1988). The average amplitude of the interpreted reflection Moho near CDP 3800 is about $10 \mathrm{~dB}$ higher than the background noise level, and the amplitude contrast between reflection $\mathrm{M}$ and the background noise supports the interpretation that $M$ is a real reflection and could be at or near the Moho. Also, the high amplitude anomaly in the lower crust represented by $\mathrm{B}$ in figure 12 could be due to actual lithologic changes rather than to processing or recording artifacts.

Another use of TA processing is to investigate variations in crustal reflectivity. Figures 11 and 12 are excellent examples of differences in crustal reflectivity. Observe the high reflectivity of the middle crust between 6-11 seconds in figure 12 and the general lack of reflectivity in that region in much of figure 11. The Moho is considerably more disruptive, discontinuous, and complicated on figure 12 compared with its banded linear geometry in much of figure 11. This kind of reflectivity of the crust provides significant information for understanding and comparing different types of crust. These are only a few examples of the advantages of TA processing for deep crustal studies. We presented three different methods for TA processing. In TA processing, high-noise bursts outside the time window for either editing or balancing a trace commonly degrade the overall quality of the seismic profile. In order to circumvent this kind of problem, we suggest some kind of surgical mute, such as automatic surgical blanking of burst noise by Bernie (1987), be applied to the trace before TA processing.

\section{CONCLUSIONS}

In summary, we can make the following conclusions based on the TA processing results from GLIMPCE seismic data:

1. All three methods can preserve the vertical amplitude variations for the deep reflections if the window for amplitude balancing is large and avoids the most heterogeneous upper crustal region.

2. Automatic editing procedure based on using the median RMS amplitude provided the best overall improvement of $S N R$.

3. All three methods generally failed to preserve true lateral amplitude variations of the deeper reflections. These variations are probably caused by changes in the transmission and attenuation properties of the nearsurface and upper crustal material rather than by shortcomings of the editing or equalization techniques. 
4. A post-stack amplitude adjustment is necessary in order to preserve the lateral variation of reflection amplitude and to reduce migration artifacts. Careful choice of the time window for post-stack adjustment is extremely important.

5. TA processing provides significant information about deep crustal seismic reflections. In addition to the conventional AGC processing, we recommend processing all deep crustal seismic data in such a way that the reflection amplitude is preserved both vertically and laterally.

\section{REFERENCES CITED}

Anstey, N.J., 1977, Seismic interpretation-The physical aspects: Boston, Mass., International Human Resources Development Corp., 637 p.

Backus, Milo M., 1987, Amplitude versus offset-A review: 57th Annual International Meeting and Exposition, Society of Exploration Geophysicists, New Orleans, expanded abstract, p. 359-364.

Behrendt, J.C., Green, A.G., Cannon, W.F., Hutchinson, D.R., Lee, M.W., Milkereit, B., Agena, W.F., and Spencer, C., 1988, Results from GLIMPCE deep seismic reflection profiles over the mid-continent rift system: Geology, v. 16 , p. 81-85.

Bernie, A.J., 1987, Automatic surgical blanking of burst noise in marine seismic data: 57th Annual International Meeting and Exposition, Society of Exploration Geophysicists, New Orleans, expanded abstract, p. 477-478.

Cannon, W.F., Green, A.G., Hutchinson, D.R., Lee, M.W., Milkereit, B., Behrendt, J.C., Halls, H.C., Green J.C., Dickas, A.B., Morey, G.B., Sutcliffe, R., and Hinze, W.J., 1989, The Midcontinent rift beneath Lake Superior-New views from GLIMPCE seismic reflection profiling: Tectonics, v. 8, p. 305-332.

Green, A.G., Milkereit, B., Davidson, A., Spencer, C.,
Hutchinson, D.R., Cannon, W.F., Lee, M.W., Agena, W.F., Behrendt, J.C., and Hinze, W.J., 1988, Crustal structure of the Grenville front and adjacent terranes: Geology, v. 16, p. 788-792.

Grow, J.A., 1980, Deep structure and evolution of the Baltimore Canyon trough in the vicinity of the COST no. B-3 well, United States mid-Atlantic continental slope area: U.S. Geological Survey Circular 833, p. 117125.

Klemperer, S.L., House, T.A., Hansen, E.C., Oliver, J.E., and Potter, C.G., 1986, The Moho in northern Basin and Range Province, Nevada, along the COCORP $40^{\circ} \mathrm{N}$ seismic-reflection transect: Geological Society of America Bulletin, v. 97, p. 603-618.

Lee, M.W., Agena, W.F., and Hutchinson, D.R., 1988, Processing of the GLIMPCE multichannel seismic data: U.S. Geological Survey Open-File Report 88-225, 46 p.

Lee, Y.N., 1960, Statistical theory of communication: London, John Wiley and Sons, 509 p.

Mayrand, L.J., and Milkereit, B., 1988, Automated editing and true amplitude stacking of seismic data: Canadian Journal of Earth Science, v. 25, p. 1811-1823.

Robinson, J.C., 1970, Statistically optimal stacking of seismic data: Geophysics, v. 35, p. 436-446.

de Voogd, B., Serpa, L., Brown, L., Hansen, E., Kaufman, S., Oliver, J., Troxel, B.W., Willemin, J., and Wright L.A., 1986, Death Valley bright spot-A midcrust magma body in the southern Great Basin, California: Geology, v. 14, p. 64-67.

Warner, Mike, 1987, Migration-Why doesn't it work for deep continental data?: Geophysical Journal of Royal Astronomical Society, v. 89, p. 21-26.

Warner, M., and McGeary, S., 1987, Seismic reflection coefficients from mantle fault zones: Geophysical Journal of Royal Astronomical Society, v. 89, p. 223-230.

Yu, G., 1985, Offset-amplitude variation and controlledamplitude processing: Geophysics, v. 50, p. 2699-2708. 


\section{APPENDIX 1.}

The condition of $S N R$ improvement by an automatic editing process for a general trace model shown in equation 1 can be derived as follows.

Let

$$
\begin{gathered}
\sum_{j=1}^{N_{1}} \alpha_{j}=\tilde{\alpha}_{m} N_{1}, \\
\sum_{j=N_{1}+1}^{N} \alpha_{j}=\tilde{\alpha}_{c} N_{2}, \\
\sum_{j=1}^{N_{1}} \beta_{j}^{2}=\tilde{\beta}_{m}^{2} N_{1}, \\
\sum_{j=N_{1}+1}^{N} \beta_{j}^{2}=\tilde{\beta}_{c}^{2} N_{2} .
\end{gathered}
$$

Then, equation 4 can be written as

$$
\frac{\tilde{\alpha}_{m}+\tilde{\alpha}_{c} q}{\sqrt{\tilde{\beta}_{m}^{2}+\tilde{\beta}_{c}^{2} q}}<\frac{\tilde{\alpha}_{m}}{\sqrt{\tilde{\beta}_{m}^{2}}}
$$

A. Signal model. - Let $\beta_{j}=1$ in equation A-1, then equation A-2 can be written as

$$
0<\tilde{\alpha}_{c}<\frac{1}{q}(\sqrt{1+q}-1) \tilde{\alpha}_{m}
$$

If the distribution of $\alpha_{j}$ is the same as in equation 5, then equation A-3 is identical to equation 7 .

B. Noise model.-Letting $\alpha_{j}=1$ in equation A-1, we can show that:

$$
\tilde{\beta}_{c}>\sqrt{(2+q)} \tilde{\beta}_{m}
$$

where $\tilde{\beta}_{c}$ or $\tilde{\beta}_{m}$ is a square root of an average of $\beta_{j}^{2}$. If the distribution $\beta_{j}$ is the same as in equation 8 , equation A-4 is identical to equation 9 .

Thus, using the average of $\alpha$ or $\beta$ defined in A-1, we can have an interpretation similar to that discussed in the main text. 



\section{SELECTED SERIES OF U.S. GEOLOGICAL SURVEY PUBLICATIONS}

\section{Perlodicals}

Earthquakes \& Volcanoes (issued bimonthly).

Preliminary Determination of Epicenters (issued monthly).

\section{Technical Books and Reports}

Professional Papers are mainly comprehensive scientific reports of wide and lasting interest and importance to professional scientists and engineers. Included are reports on the results of resource studies and of topographic, hydrologic, and geologic investigations. They also include collections of related papers addressing different aspects of a single scientific topic.

Bulletins contain significant data and interpretations that are of lasting scientific interest but are generally more limited in scope or geographic coverage than Professional Papers. They include the results of resource studies and of geologic and topographicinvestigations; as well as collections of short papers related to a specific topic.

Water-Supply Papers are comprehensive reports that present significant interpretive results of hydrologic investigations of wide interest to professional geologists, hydrologists, and engineers. The series covers investigations in all phases of hydrology, including hydrogeology, availability of water, quality of water, and use of water.

Circulars present administrative information or important scientific information of wide popular interest in a format designed for distribution at no cost to the public. Information is usually of short-term interest.

Water-Resources Investigations Reports are papers of an interpretive nature made available to the public outside the formal USGS publications series. Copies are reproduced on request unlike formal USGS publications, and they are also available for public inspection at depositories indicated in USGS catalogs.

Open-File Reports include unpublished manuscript reports, maps, and other material that are made available for public consultation at depositories. They are a nonpermanent form of publication that may be cited in other publications as sources of information.

\section{Maps}

Geologic Quadrangle Maps are multicolor geologic maps on topographic bases in $71 / 2$ - or 15 -minute quadrangle formats (scales mainly $1: 24,000$ or $1: 62,500$ ) showing bedrock, surficial, or engineering geology. Maps generally include brief texts; some maps include structure and columnar sections only.

Geophysical Investigations Maps are on topographic or planimetric bases at various scales; they show results of surveys using geophysical techniques, such as gravity, magnetic, seismic, or radioactivity, which reflect subsurface structures that are of economic or geologic significance. Many maps include correlations with the geology.

Miscellaneous Investigations Series Maps are on planimetric or topographic bases of regular and irregular areas at various scales; they present a wide variety of format and subject matter. The series also includes $71 / 2$-minute quadrangle photogeologic maps on planimetric bases which show geology as interpreted from aerial photographs. Series also includes maps of Mars and the Moon.
Coal Investigations Maps are geologic maps on topographic or planimetric bases at various scales showing bedrock or surficial geology, stratigraphy, and structural relations in certain coal-resource areas.

Oil and Gas Investigations Charts show stratigraphic information for certain oil and gas fields and other areas having petroleum potential.

Miscellaneous Field Studies Maps are multicolor or black-andwhite maps on topographic or planimetric bases on quadrangle or irregular areas at various scales. Pre-1971 maps show bedrock geology in relation to specific mining or mineral-deposit problems; post-1971 maps are primarily black-and-white maps on various subjects such as environmental studies or wildemess mineral investigations.

Hydrologic Investigations Atlases are multicolored or black-andwhite maps on topographic or planimetric bases presenting a wide range of geohydrologic data of both regular and irregular areas; principal scale is $1: 24,000$ and regional studies are at $1: 250,000$ scale or smaller.

\section{Catalogs}

Permanent catalogs, as well as some others, giving comprehensive listings of U.S. Geological Survey publications are available under the conditions indicated below from the U.S. Geological Survey, Books and Open-File Reports Section, Federal Center, Box 25425, Denver, CO 80225. (See latest Price and Availability List.)

"Publications of the Geological Survey, 1879- 1961" may be purchased by mail and over the counter in paperback book form and as a set of microfiche.

"Publications of the Geological Survey, 1962-1970" may be purchased by mail and over the counter in paperback book form and as a set of microfiche.

"Publications of the U.S. Geological Survey, 1971- 1981" may be purchased by mail and over the counter in paperback book form (two volumes, publications listing and index) and as a set of microfiche.

Supplements for 1982, 1983, 1984, 1985, 1986, and for subsequent years since the last permanent catalog may be purchased by mail and over the counter in paperback book form.

State catalogs, "List of U.S. Geological Survey Geologic and Water-Supply Reports and Maps For (State)," may be purchased by mail and over the counter in paperback booklet form only

"Price and Availability List of U.S. Geological Survey Publications," issued annually, is available free of charge in paperback booklet form only.

Selected coples of a monthly catalog "New Publications of the U.S. Geological Survey" available free of charge by mail or may be obtained over the counter in paperback booklet form only. Those wishing a free subscription to the monthly catalog "New Publications of the U.S. Geological Survey" should write to the U.S. Geological Survey, 582 National Center, Reston, VA 22092.

Note.--Prices of Government publications listed in older catalogs, announcements, and publications may be incorrect. Therefore, the prices charged may differ from the prices in catalogs, announcements, and publications. 
